\title{
ENDOGENOUS MARKET STRUCTURES AND THE BUSINESS CYCLE ${ }^{1}$
}

\author{
Federico Etro and Andrea Colciago \\ University of Milano, Bicocca, Department of Economics \\ forthcoming on The Economic Journal \\ First version: September 2007 \\ Current version: October 2009
}

\begin{abstract}
We characterize endogenous market structures under Bertrand and Cournot competition in a DSGE model. Short run markups vary countercyclically because of the impact of entry on competition. Long run markups are decreasing in the discount factor and in productivity, and increasing in the exit rate and in the entry costs. Dynamic inefficiency can emerge due to excessive entry under Cournot competition. Positive temporary shocks attract entry, which strengthens competition so as to temporary reduce the markups and increase real wages: this competition effect creates an intertemporal substitution effect which boosts consumption and employment. Endogenous market structures improve the ability of a flexible prices model in matching impulse response functions and second moments for US data.
\end{abstract}

JEL classification: L11, E32.

Keywords: Endogenous Market Structure, Firms' Entry, Business Cycle.

\footnotetext{
${ }^{1}$ This work is part of a larger research project which includes the companion paper "Ramsey Meets Cournot" (Colciago and Etro, 2007). We are grateful to seminar participants at the University of Saint Andrews, CERGE-EI (Prague), University of Amsterdam, the IMT (Lucca), the University of Rome, the University of Milan, Bicocca, the Catholic University of Leuven, the University of Osaka, the University of Tokyo and the Central Bank of Hungary for important suggestions. Guido Ascari, John Beath, Florin Bilbiie, Lilia Cavallari, Alex Cuckierman, Alberto Dalmazzo, Mark Gertler, Fabio Ghironi, Mario Gilli, Stefano Gnocchi, Giammario Impullitti, Pietro Peretto, Tiziano Ropele and Patrizio Tirelli provided insightful discussions on this topic. Correspondence: Federico Etro, University of Milano-Bicocca, Department of Economics, U6-360, Piazza dell'Ateneo Nuovo 1, Milano 20126, Italy.
} 
The neoclassical theory of the business cycle, which is well represented by the work of Kydland and Prescott (1982), is based on perfect competition, constant returns to scale and the absence of fixed costs of production. In this environment goods are priced at the marginal cost, there is no room for extraprofits and the structure of the markets is indeterminate, i.e. mark ups are zero and the number of firms, their individual production and (stock market) values are not determined by the model. The New-Keynesian theory, starting with Blanchard and Kiyotaki (1987), has introduced product differentiation and imperfect competition in general equilibrium models with nominal frictions to study the effects of aggregate demand and supply shocks. Most of this literature departed from the neoclassical framework assuming monopolistic competition à la Dixit and Stiglitz (1977) between an exogenous number of firms producing differentiated goods. This approach rapidly became the standard framework for the analysis of macroeconomic policy, with a focus on monetary policy. Nevertheless, it also led to exogenous market structures. As such, it neglected the role of strategic interactions between firms of the same sectors, the endogeneity of the number of competitors, and the impact of entry on the same strategic interactions. The result is that the structure of the sectors of the economy remains a sort of "black box" whose main components, mark ups, number of competitors and their individual production level, are exogenous in the short and long run.

Building on recent important works on entry by Ghironi and Melitz (2005) and Bilbiie, Ghironi and Melitz (2007, BGM henceforth) $)^{2}$ we open the "black box" of the market structure, we introduce strategic interactions and link the endogenous behavior of firms at the sectorial level with the general equilibrium properties of the economy, in particular with its business cycle properties. We consider an economy with distinct sectors, each one characterized by many firms supplying goods that can be imperfectly substitutable to a different degree, taking strategic interactions into account and competing either in prices (Bertrand competition) or in quantities (Cournot competition). Sunk entry costs allow us to endogenize entry and the (stock market) value of each firm in each sector. Therefore, in the short run the degree of market power depends endogenously on the form of competition, on the degree of substitutability between goods and on the number of firms.

In the long run, the equilibrium mark ups depend also on the structural parameters of the economy: they are decreasing in the discount factor of consumers and in the productivity level, and increasing in the rate of exit from the market and in the size of the costs of entry. The long run endogenous market structure is typically inefficient because of the tendency toward excessive entry associated with imperfect competition. Moreover, since savings finance the process of business creation, this can lead to a novel form of dynamic inefficiency (compared to the neoclassical framework or the BGM model). In particular, under Cournot competition, when the discount factor is high enough, the number of firms is above the "golden rule" number that would maximize steady state utility: when consumers are extremely patient they save too much, inducing excessive creation of firms that produce too little individually.

While the market for goods is characterized by imperfect competition and endogenous entry, the rest of our baseline economy operates as in a standard neoclassical (flexible price) model without accumulation of physical capital. In this context, a temporary supply shock initially increases profits, which attracts entry of firms and strengthens competition, which

\footnotetext{
${ }^{2}$ Early contributions to this literature are Chattejee and Cooper (1993), Devereux et al. (1996), Cooper (1999), Devereux and Lee (2001). More recent developments are in BGM (2007, 2008a,b), Elkhoury and Mancini-Griffoli (2007), Etro (2007), Bergin and Corsetti (2008), Jaimovich and Floetotto (2008) and Lewis (2009). For other applications of endogenous market structures in macroeconomic models see Etro (2009a, 2010).
} 


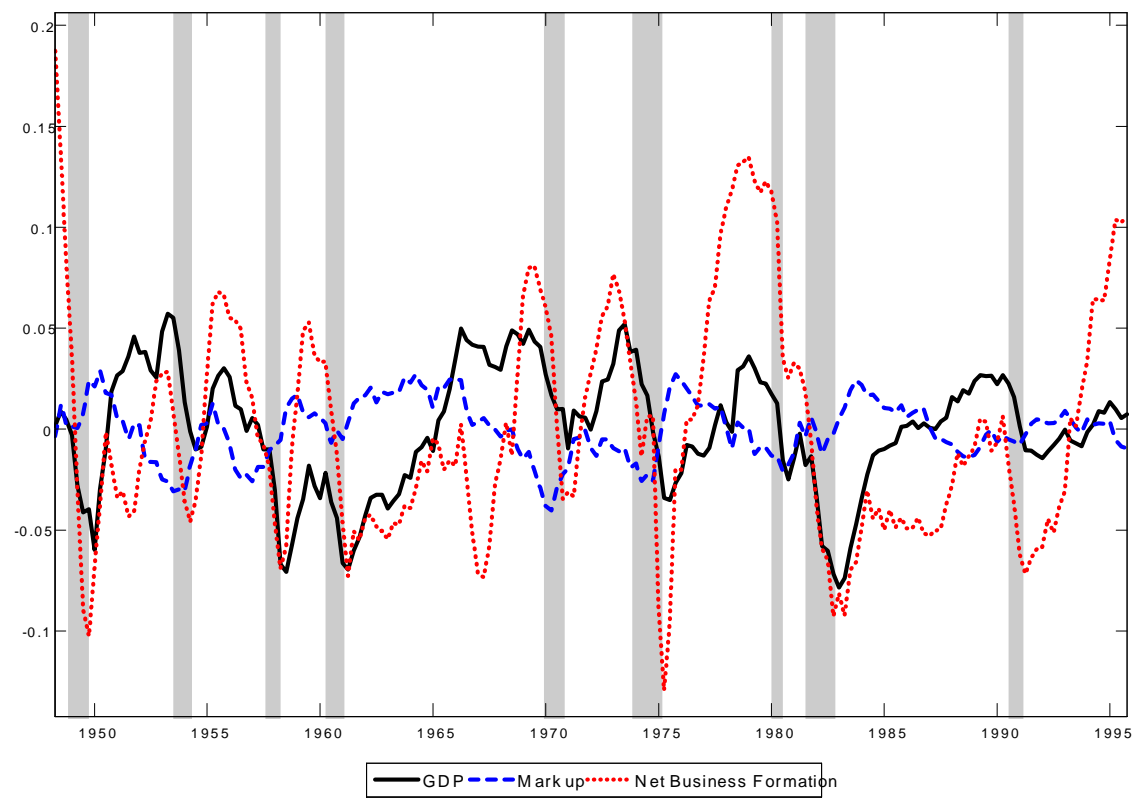

Figure 1: Cyclical component of GDP, Net Business formation and Price Markup. Shaded areas represent NBER recessions.

in turn reduces the mark ups and (through a general equilibrium effect) increases the real wages. The temporary reduction of mark ups and increase of real wages induces a stronger intertemporal substitution effect in favor of current consumption and labor supply, which magnifies the effects of the shock compared to a perfectly competitive model $a$ la Kydland and Prescott (1982). Our propagation mechanism is even stronger when we augment the model with physical capital.

There is convincing macroeconomic evidence in support of the business cycle implications of our approach. Bils (1987), Rotemberg and Woodford (1999) and Galì et al. (2007) document price mark ups countercyclicality. Early references on the procyclicality of firms' entry are Chatterjee and Cooper (1993) for the US and Portier (1995) for France. BGM (2007) emphasize the procyclicality of real profits. To provide additional support to these empirical findings we performed a VAR analysis on US data. We constructed a labor share based measure of the price mark up for the US along the lines suggested by Rotemberg and Woodford (1999) in their analysis of cyclical mark up behavior. ${ }^{3}$ Figure 1 plots the series of detrended GDP, the markup and an index of net business formation at a quarterly

\footnotetext{
${ }^{3}$ Rotemberg and Woodford (1999) assume the existence of overhead labor $L_{t}^{o}$ so that effective labor for the production of consumption goods is $L_{t}^{c}=L_{t}-L_{t}^{o}$ where $L_{t}$ total labor supply. In this case the equilibrium markup in a model with a production function $Y_{t}=A_{t} L_{t}^{c}$ can be written as $\mu_{t}=A_{t} / w_{t}=\left(Y_{t} / w_{t} L_{t}\right) L_{t} /\left(L_{t}-L_{t}^{o}\right)$, whose log-linearization is $\widehat{\mu}_{t}=-l^{o} \hat{L}_{t} /\left(1-l^{o}\right)-\widehat{s}_{t}$, where $l^{o} \equiv L^{o} / L$ represents the average share of overhead labor over total labor input (assumed to be equal to 0.2$), s_{t} \equiv w_{t} L_{t} / Y_{t}$ is the labor share of income, and hatted variables indicate percentage deviations from its long run trend.
} 
frequency from 1948:1 to 1995:3. ${ }^{4}$ In line with the evidence reviewed above, net business formation is procyclical and negatively correlated with the mark up, which is countercyclical. The contemporaneous correlation between GDP and new business formation is positive and equals 0.45 , while that between GDP and the price mark up is $-0.42 .{ }^{5}$ Next we considered a $\operatorname{VAR}(2)$ model including our mark up measure, a measure of the Solow residual corrected for the presence of market structure endogeneity, which we take as the measure of technology ${ }^{6}$ consumption, GDP, profits, and the index of net business formation. We identify the technology shock by imposing a recursive structure on the system. In our baseline specification variables are ordered as listed above. ${ }^{7}$ The ordering is naturally suggested by our theoretical framework. The technology shock affects output and consumption, this leads, for given markup, to a change in profits which affects the entry decision of firms. The resulting number of competitors will finally lead to a mark up change. Figure 2 shows the estimated responses to an expansionary shock to technology. The responses of output and consumption are similar to those found in Dedola and Neri (2007) and other works in the literature. Most relevantly for our purposes, both profits and firm entry respond positively to the technology shock, while the price mark up declines significantly. This endogenous reaction is consistent with the hypothesis formulated in our approach.

Our work is related to some recent theoretical and empirical contributions studying the role of firms' entry and the creation of new products. ${ }^{8}$ Recent empirical works on the manufacturing sector by Broda and Weinstein (2009) and Bernard et al. (2008) have emphasized the importance of the extensive margin in the process of product creation or innovation. For this reason BGM (2007) design the entry process as a process of creation of new products with limited substitutability which may depend on the same number of available products. This relation between number of goods and their substitutability can be microfounded through the translog preferences introduced by Feenstra (2003), which are characterized by demand-side pricing complementarities. While driven by different mechanisms, both the BGM demand side explanation and our supply side explanation deliver dynamic responses of mark ups and profits to a technology shock which are consistent with the VAR evidence presented above.

Early works of the New Empirical Industrial Organization literature starting with Bresnahan and Reiss (1987) and more recent research by Manuszak (2002), Campbell and Hopenhayn (2005), Manuszak and Moul (2008) and others have provided convincing evidence in

\footnotetext{
${ }^{4}$ Variables have been logged. Since we use these variables in subsequent time series analysis we opt for a polynomial of time to detrend variables instead of the HP filter, as suggested by Galì et al. (2007). However the signs of contemporaneous correlations between our measures of entry and the price mark up with output are unchanged when variables are detrended using the HP filter.

${ }^{5}$ The $95 \%$ confidence intervals are respectively $(0.33 \div 0.56)$ and $(-0.53 \div-0.3)$. Both correlation coefficients are statistically different from zero. The contemporaneous correlation between GDP and the number of new incorporations is positive too and equals 0.11 , but it is statistically different from zero at the 10 percent significance level. However in the time series analysis we adopt the number of new incorporations as a mesure of net entry, since it is closer to what we consider as new entrants.

${ }^{6}$ Jaimovich (2007) and Jaimovich and Floetotto (2008) argue that the Solow Residual is a biased measure of technology in the presence of mark up variability. See the Appendix for our derivation of a model consistent correction of the Solow Residual.

${ }^{7}$ The lag length has been selected according to a sequential LR test starting with a maximum number of lags equal to 8 . However results do not change relevantly if we consider 3 or 4 lags. For robustness we experimented with alternative orderings of the variables ordered after technology. Also we have estimated the dynamic behaviour of the model including the number of new incorporations described above instead of the index measuring new business formation. In all these cases just minor changes apply to the our baseline results.

${ }^{8} \mathrm{An}$ emerging theoretical literature is analyzing endogenous market structures in partial and general equilibrium contexts. Between the recent works focusing on dynamic entry we should cite at least Kováč et al. (2009) and Denicolò and Zanchettin (2010).
} 

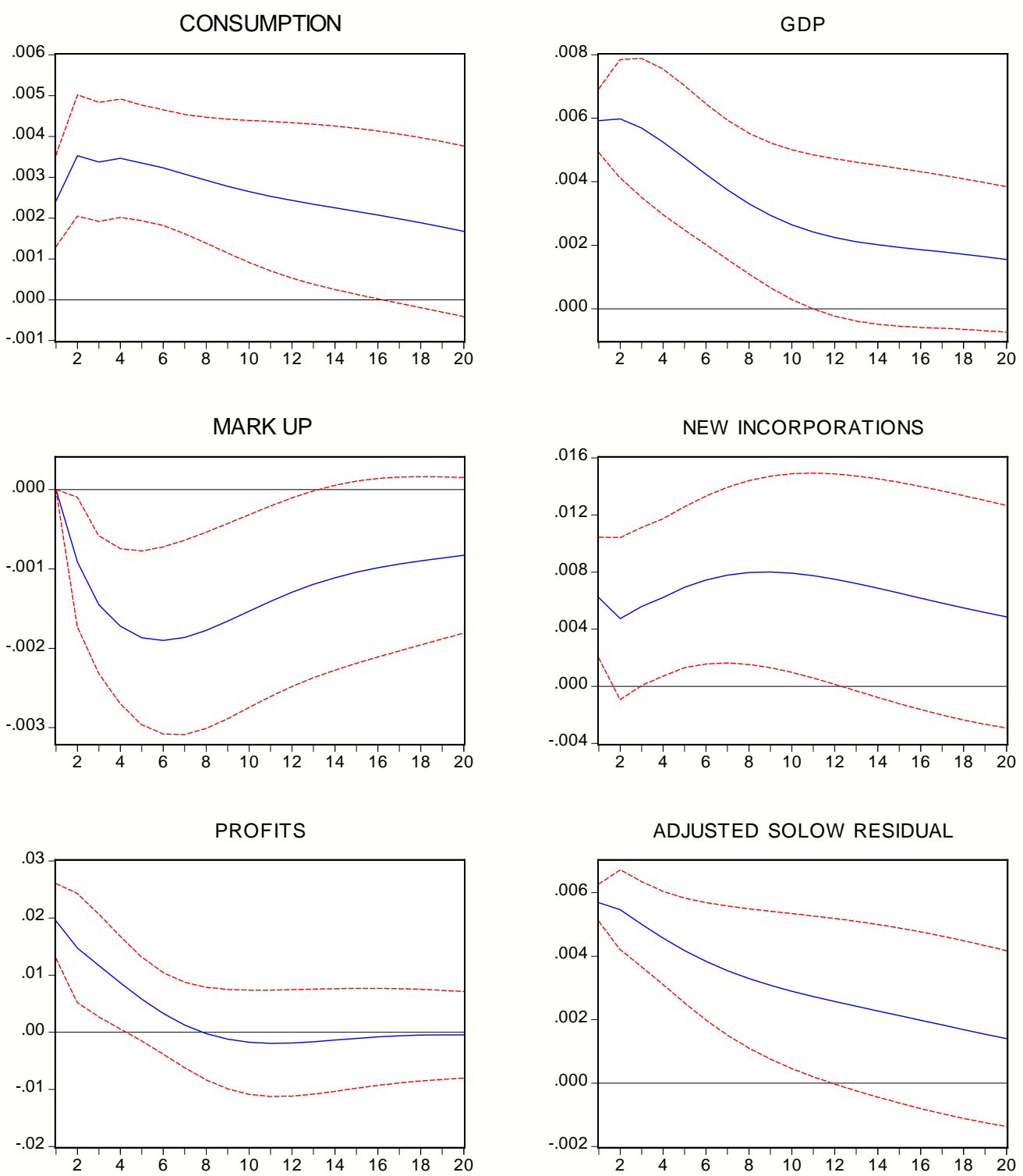

Figure 2: VAR(2) model. IRFs to a technology shock with 95 percent confidence bands. 
support of the competition effect on mark ups and the number of firms. However, while this empirical literature refers to a supply-side explanation for countercyclical mark ups, its results may be consistent also with the demand-side explanation proposed by BGM (2007). Future research may try to identify and disentangle demand and supply effects by means of microeconomic data.

Jaimovich and Floetotto (2008) have independently developed a flexible price model with endogenous market structures. Our analysis differs from theirs with respect to both assumptions and focus. For what concerns assumptions, as mentioned above, we model endogenous entry à la Ghironi and Melitz (2005) rather then resorting to a static zero profits condition. This allows us to study the interaction between entry costs and oligopolistic behavior in the short and the long run. To account for the degree of business destruction we assume that an exogenous fraction of firms exits the market in each period, which makes the number of active firms an endogenous state variable. This helps reproducing two relevant empirical regularities: the first is a positive correlation between profits and output together with the negative correlation between mark ups and output, and the second one is the nonlinear time profile of the correlation between the markup and the cycle. In our framework output jumps on impact in response to a TFP shock, while, since the number of firms increases slowly, the mark up does not change on impact and falls more in future periods. ${ }^{9}$ This correlation pattern is consistent with the VAR analysis presented above. ${ }^{10}$ With respect to the focus, we analyze endogenous market structures both in the long and the short run, and we emphasize their role under different forms of competition for the propagation of exogenous technology shocks. Jaimovich and Floetotto (2008) consider the effects of market structure endogeneity for the measurement of the Solow residual. More precisely, they exploit the market structure endogeneity to provide a decomposition of TFP in an exogenous component and in an endogenous one due to the variability of mark ups. By fitting a AR(1) process to the exogenous component of technology obtained with this methodology, they find that the latter has a lower variability with respect to that estimated using the traditional measures of the Solow residual. Next they impose the estimated TFP process on model characterized by strategic interactions and show that this can outperform the standard RBC model at replicating the variability of the main macroeconomic variables.

The remainder of the paper is organized as follows. Section 1 describes the model and its dynamic properties in the short and long run. Section 2 calibrates and simulates the model. Section 3 compares our supply-side explanation for countercyclical mark ups with the demand-side explanation based on translog preferences. Section 4 augments the model with physical capital. Section 5 concludes. Technical details are left in the Appendix.

\section{The Model}

Consider a representative agent with utility:

$$
U=E_{0} \sum_{t=0}^{\infty} \beta^{t}\left\{\int_{0}^{1} \log C_{k t} d k-v \frac{L_{t}^{1+1 / \varphi}}{1+1 / \varphi}\right\} \quad v, \varphi \geq 0
$$

\footnotetext{
${ }^{9}$ We thank a referee for pointing this out.

${ }^{10}$ Jaimovich and Floetotto (2008) circulated an online appendix with a version of their paper featuring sunk entry costs and a dynamic of the number of firms similar to that adopted in the working paper version of this article ("Endogenous Market Structures and the Business Cycle", November 2007, WP 126, University of Milan, Bicocca). Our model has been developed independently of their analysis, and had already been circulating when we became aware of their extension.
} 
where $\beta \in(0,1)$ is the discount factor, $L_{t}$ is labor supply and $C_{k t}$ is a consumption index for a continuum of goods produced in sectors $k \in[0,1]$. The representative agent supplies labor for a nominal wage $W_{t}$ and allocates his or her savings between bonds or stocks. The intratemporal optimality conditions for the optimal choices of $C_{k t}$ and $L_{t}$ require:

$$
\begin{gathered}
P_{k t} C_{k t}=E X P_{t} \text { for any } k \\
\left(\frac{W_{t}}{P_{k t}}\right) C_{k t}^{-1}=v L_{t}^{\frac{1}{\varphi}}
\end{gathered}
$$

where $E X P_{t}$ is total nominal expenditure allocated to the goods produced in each sector in period $t$ and $P_{k t}$ is the price index for consumption in sector $k$ : due to the unitary elasticity of substitution, total expenditure is equally shared between the sectors.

Each sector $k$ is characterized by different firms $i=1,2, \ldots, N_{k t}$ producing the same good in different varieties, and the consumption index $C_{k t}$ is:

$$
C_{k t}=\left[\sum_{i=1}^{N_{k t}} C_{k t}(i)^{\frac{\theta-1}{\theta}}\right]^{\frac{\theta}{\theta-1}}
$$

where $C_{k t}(i)$ is the production of firm $i$ of this sector, and $\theta>1$ is the elasticity of substitution between the goods produced in each sector. The distinction between different sectors and different goods within a sector allows to realistically separate limited substitutability at the aggregated level, and high substitutability at the disaggregated level. Contrary to many macroeconomic models with imperfect competition, our focus will be on the market structure of disaggregated sectors: intrasectoral substitutability (between goods produced by firms of a same sector) is high, while intersectoral substitutability is low. ${ }^{11}$

Each firm $i$ in sector $k$ produces a good with a linear production function. For the moment we abstract from capital accumulation issues and assume that labor is the only input. Output of firm $i$ in sector $k$ is then:

$$
y_{k t}(i)=A_{t} L_{k t}^{c}(i)
$$

where $A_{t}$ is total factor productivity at time $t$, and $L_{k t}^{c}(i)$ is labor employed for the production of the consumption good by firm $i$ in sector $k$. This implies that the production of one good requires $1 / A_{t}$ units of labor, and the nominal marginal cost of production is $W_{t} / A_{t}$.

Since each sector can be characterized in the same way, in what follows we will drop the index $k$ and refer to the representative sector (further details are provided in Appendix A).

\subsection{Endogenous Market Structures in the short run}

In each period, the same expenditure for each sector $E X P_{t}$ is allocated across the available goods according to the direct demand function derived from the maximization of the consumption index (4):

$$
C_{t}(i)=C_{t}\left(\frac{p_{t}(i)}{P_{t}}\right)^{-\theta}=\frac{p_{t}(i)^{-\theta}}{P_{t}^{1-\theta}} C_{t} P_{t}=\frac{p_{t}(i)^{-\theta} E X P_{t}}{P_{t}^{1-\theta}} \quad i=1,2, \ldots, N_{t}
$$

\footnotetext{
${ }^{11}$ In particular our functional form implies unitary elasticity of substitution between sectors. The same approach has been independently proposed by Atkeson and Burnstein (2008) in a trade model. Even if they allow for general substitutability across sectors, their numerical results are obtained assuming a unitary intersectoral elasticity of substitution.
} 
where $P_{t}$ is the standard price index:

$$
P_{t}=\left[\sum_{j=1}^{N_{t}} p_{t}(j)^{-(\theta-1)}\right]^{\frac{-1}{\theta-1}}
$$

such that total expenditure satisfies $E X P_{t}=\sum_{j=1}^{N_{t}} p_{t}(j) C_{t}(j)=C_{t} P_{t}$. Inverting the direct demand functions, we can derive the system of inverse demand functions:

$$
p_{t}(i)=\frac{x_{t}(i)^{-\frac{1}{\theta}} E X P_{t}}{\sum_{j=1}^{N_{t}} x_{t}(j)^{\frac{\theta-1}{\theta}}} \quad i=1,2, \ldots, N_{t}
$$

where $x_{t}(i)$ is the consumption of good $i$.

We assume that firms cannot credibly commit to a sequence of strategies, therefore their behavior is equivalent to maximize current profits in each period taking as given the strategies of the other firms. Each good is produced at the constant marginal cost common to all firms. A main interest of this article is in the comparison of equilibria where in each period firms compete in prices and in quantities, taking as given their marginal cost of production and the aggregate expenditure of the representative consumer. ${ }^{12}$ Under different forms of competition we obtain symmetric equilibrium prices satisfying:

$$
p_{t}=\frac{\mu\left(\theta, N_{t}\right) W_{t}}{A_{t}}
$$

where $\mu\left(\theta, N_{t}\right)>1$ is the mark up depending on the degree of substitutability between goods $\theta$ and on the number of firms $N_{t}$. In the next sections we characterize this mark up under competition in prices and in quantities taking strategic interactions into account. ${ }^{13}$

\subsubsection{Bertrand competition}

Let us consider competition in prices (with symmetric equilibria). In each period, the gross profits of firm $i$ can be expressed as:

$$
\Pi_{t}\left[p_{t}(i)\right]=\frac{\left[p_{t}(i)-W_{t} / A_{t}\right] p_{t}(i)^{-\theta} E X P_{t}}{\left[\sum_{j=1}^{N_{t}} p_{t}(j)^{-(\theta-1)}\right]}
$$

Firms compete by choosing their prices. Contrary to the traditional Dixit-Stiglitz (1977) approach which neglects strategic interactions between firms, we will take these into consideration and derive the exact Bertrand equilibrium. Each firm $i$ chooses the price $p_{t}(i)$ to maximize profits taking as given the price of the other firms. ${ }^{14}$ The first order condition for

\footnotetext{
${ }^{12}$ Of course, both of them are endogenous in general equilibrium, but it is reasonable to assume that firms do not perceive marginal cost and aggregate expenditure in the sector as affected by their choices.

${ }^{13}$ In the companion paper (Colciago and Etro, 2007) we have examined other forms of competition as imperfect collusion (through the model of quantity competition with conjectural variations) and Stackelberg competition with a leader choosing production before the followers.

${ }^{14}$ Since total expenditure $E X P_{t}$ is equalized between sectors by the consumers, we assume that it is also perceived as given by the firms. Under the alternative hypothesis that consumption is perceived as given, we would obtain a higher mark up (as in Yang and Heijdra, 1993) which would lead to similar qualitative results.
} 
any firm $i$ is:

$$
\left\{p_{t}(i)^{-\theta}-\theta\left[p_{t}(i)-\frac{W_{t}}{A_{t}}\right] p_{t}(i)^{-\theta-1}\right\}=\frac{(1-\theta) p_{t}(i)^{-\theta}\left[p_{t}(i)-\frac{W_{t}}{A_{t}}\right] p_{t}(i)^{-\theta}}{\sum_{i=1}^{N_{t}} p_{t}(i)^{1-\theta}}
$$

Notice that the term on the right hand side is the effect of the price strategy of a firm on the price index: higher prices reduce overall demand, therefore firms tend to set higher mark ups compared to monopolistic competition à la Dixit-Stigliz. Imposing symmetry between the $N_{t}$ firms, the equilibrium price $p_{t}$ must satisfy:

$$
\left[p_{t}^{-\theta}-\theta\left(p_{t}-\frac{W_{t}}{A_{t}}\right) p_{t}^{-\theta-1}\right] N_{t} p_{t}^{-(\theta-1)}=(\theta-1) p_{t}^{-\theta}\left(p_{t}-\frac{W_{t}}{A_{t}}\right) p_{t}^{-\theta}
$$

Solving for the equilibrium we have $p_{t}=W_{t}\left(\theta N_{t}+\theta-1\right) / A_{t}(\theta-1)\left(N_{t}-1\right)$, which generates the mark up: ${ }^{15}$

$$
\mu^{P}\left(\theta, N_{t}\right)=\frac{1+\theta\left(N_{t}-1\right)}{(\theta-1)\left(N_{t}-1\right)}
$$

where the index $P$ stands for competition in prices. The mark up is decreasing in the degree of substitutability between products $\theta$, with an elasticity $\epsilon_{\theta}^{P}=\theta N_{t} /\left(1-\theta+\theta N_{t}\right)(\theta-1)$. Moreover, the mark up vanishes in case of perfect substitutability: $\lim _{\theta \rightarrow \infty} \mu^{P}\left(\theta, N_{t}\right)=$ 1. Finally, the mark up is decreasing in the number of firms, with an elasticity $\epsilon_{N}^{P}=$ $N /[1+\theta(N-1)](N-1)$. Notice that the elasticity of the mark up to entry under competition in prices is decreasing in the level of substitutability between goods, and it tends to zero when the goods are approximately homogenous. Finally, when $N_{t} \rightarrow \infty$ the markup tends to $\theta /(\theta-1)$, the traditional one under monopolistic competition (and adopted by BGM, 2007). As well known, strategic interactions between a finite number of firms lead to a higher markup than under monopolistic competition. In conclusion, with competition in prices the individual profits can be expressed in real terms (that is dividing nominal profits by the price index $P_{t}$ ) as:

$$
\pi_{t}^{P}\left(\theta, N_{t}\right)=\frac{C_{t}}{1+\theta\left(N_{t}-1\right)}
$$

which is a decreasing function of the number of firms and of the substitutability between goods.

\subsubsection{Cournot competition}

Let us consider competition in quantities (again focusing on symmetric equilibria). Using the inverse demand function (8), we can express the profit function of a firm $i$ as a function of its output $x_{t}(i)$ and the output of all the other firms:

$$
\begin{aligned}
\Pi_{t}\left[x_{t}(i)\right] & =\left[p_{t}(i)-\frac{W_{t}}{A_{t}}\right] x_{t}(i)= \\
& =\frac{x_{t}(i)^{\frac{\theta-1}{\theta}} E X P_{t}}{\sum_{j=1}^{N_{t}} x_{t}(j)^{\frac{\theta-1}{\theta}}}-\frac{W_{t} x_{t}(i)}{A_{t}}
\end{aligned}
$$

\footnotetext{
${ }^{15}$ Jaimovich and Floetotto (2008) allow for a general value of the intersectoral elasticty of substitution. In this case the individual firm also considers the effect of its pricing strategy on the sectoral price level.
} 
Assume now that each firm chooses its production $x_{t}(i)$ taking as given the production of the other firms. The first order conditions:

$$
\left(\frac{\theta-1}{\theta}\right) \frac{x_{t}(i)^{-\frac{1}{\theta}} E X P_{t}}{\sum_{j} x_{t}(j)^{\frac{\theta-1}{\theta}}}-\left(\frac{\theta-1}{\theta}\right) \frac{x_{t}(i)^{\frac{\theta-2}{\theta}} E X P_{t}}{\left[\sum_{j} x_{t}(j)^{\frac{\theta-1}{\theta}}\right]^{2}}=\frac{W_{t}}{A_{t}}
$$

for all firms $i=1,2, \ldots, N_{t}$ can be simplified imposing symmetry of the Cournot equilibrium. This generates the individual output:

$$
x_{t}=\frac{(\theta-1)\left(N_{t}-1\right) A_{t} E X P_{t}}{\theta N_{t}^{2} W_{t}}
$$

Substituting into the inverse price, one obtains the equilibrium price $p_{t}=W_{t} \theta N_{t} / A_{t}(\theta-$ 1) $\left(N_{t}-1\right)$, which is associated with the equilibrium mark up:

$$
\mu^{Q}\left(\theta, N_{t}\right)=\frac{\theta N_{t}}{(\theta-1)\left(N_{t}-1\right)}
$$

where the index $Q$ stands for competition in quantities. For a given number of firms, the mark up under competition in quantities is always larger than the one obtained before under competition in prices, as well known for models of product differentiation (see for instance Vives, 1999). Notice that the mark up is decreasing in the degree of substitutability between products $\theta$, with an elasticity $\epsilon_{\theta}^{Q}=1 /(\theta-1)$, which is always smaller than $\epsilon_{\theta}^{P}$ : higher substitutability reduces mark ups faster under competition in prices than under competition in quantities.

In the Cournot equilibrium, the markup remains positive for any degree of substitutability, since even in the case of homogenous goods, we have $\lim _{\theta \rightarrow \infty} \mu^{Q}\left(\theta, N_{t}\right)=N_{t} /\left(N_{t}-1\right)$. This allow us to consider the effect of strategic interactions in an otherwise standard setup with perfect substitute goods within sectors.

In the general formulation the markup is decreasing and convex in the number of firms with elasticity $\epsilon_{N}^{Q}=1 /(N-1)$, which is decreasing in the number of firms (the mark up decreases with entry at an increasing rate) and independent from the degree of substitutability between goods. Since $\epsilon_{N}^{Q}>\epsilon_{N}^{P}$ for any number of firms or degree of substitutability, we can conclude that entry decreases mark ups faster under competition in quantities compared to competition in prices, a result that will have an impact on the relative behavior of the economy under the two forms of competition. Finally, only when $N_{t} \rightarrow \infty$ the markup tends to $\theta /(\theta-1)$, which is the traditional markup under monopolistic competition. The individual profits in real terms can be expressed as:

$$
\pi_{t}^{Q}\left(\theta, N_{t}\right)=\frac{\left(N_{t}+\theta-1\right) C_{t}}{\theta N_{t}^{2}}
$$

which is a decreasing function of the number of firms and of the degree of substitutability.

\subsubsection{Endogenous Entry}

In this model, households choose how much to save in riskless bonds and in the creation of new firms through the stock market according to standard Euler and asset pricing equations. Following Ghironi and Melitz (2005) and BGM (2007), the average number of firms per sector follows the equation of motion:

$$
N_{t+1}=(1-\delta)\left(N_{t}+N_{t}^{e}\right)
$$


where $N_{t}^{e}$ is the average number of new firms and $\delta \in(0,1)$ is the exogenous rate of exit. ${ }^{16}$ The real value of a firm $V_{t}$ is the present discounted value of its future expected profits, or in recursive form:

$$
V_{t}=\beta(1-\delta) E_{t}\left[\frac{V_{t+1}+\pi_{t+1}\left(\theta, N_{t+1}\right)}{1+r_{t+1}}\right]
$$

where $r_{t}$ is the real interest rate. We assume that entry requires a fixed cost of production in units of labor. This implies that technology shocks affect the productivity of the workers that produce goods and also of the workers that create new business: this appears as the most natural hypothesis, but our main results would go through in case of fixed costs in units of consumption. Therefore, we assume that the entry cost equals $\eta / A_{t}$ units of labor, with $\eta>0$. In each period entry is determined endogenously to equate the value of firms to the entry costs. Since the real cost of a unit of labor can be derived from the equilibrium pricing relation (9) as:

$$
w_{t}=\frac{A_{t} p_{t}}{\mu\left(\theta, N_{t}\right) P_{t}}=\frac{A_{t} N_{t}^{1 /(\theta-1)}}{\mu\left(\theta, N_{t}\right)}
$$

where we used the fact that $P_{t}=p_{t} N_{t}^{1 /(1-\theta)}$ in the symmetric equilibrium, the endogenous value of a single firm must be equal to the fixed cost of entry, or:

$$
V_{t}=\frac{\eta N_{t}^{1 /(\theta-1)}}{\mu\left(\theta, N_{t}\right)}
$$

The representative agent supplies labor which is employed to produce goods and to create new firms. Market clearing in the markets for goods, labor and credit determines the dynamics of the economy, which can be expressed in terms of a system of two equations for the evolution of $N_{t}$ and $C_{t}$ (eventually depending on the evolution of total factor productivity $\left.A_{t}\right)$. We leave the details of the derivation to the Appendix and report here the equilibrium relations for the number of firms and for consumption of the representative agent, derived by substituting all the equilibrium conditions into (17) and (18).

In particular, under competition in prices we have:

$$
\begin{gathered}
N_{t+1}=(1-\delta)\left[N_{t}+\frac{A_{t}^{1+\varphi}}{\eta}\left(\frac{(\theta-1)\left(N_{t}-1\right) N_{t}^{\frac{1}{\theta-1}}}{v\left[1+\theta\left(N_{t}-1\right)\right] C_{t}}\right)^{\varphi}-\frac{C_{t}}{\eta N_{t}^{1 /(\theta-1)}}\right] \\
E_{t}\left\{\left(\frac{C_{t+1}}{C_{t}}\right)^{-1}\left[\frac{\eta(\theta-1)\left(N_{t}-1\right) N_{t}^{\frac{1}{\theta-1}}}{1+\theta\left(N_{t}-1\right)}+\frac{C_{t+1}}{1+\theta\left(N_{t+1}-1\right)}\right]\right\}=\frac{\eta(\theta-1)\left(N_{t}-1\right) N_{t}^{\frac{1}{\theta-1}}}{\beta(1-\delta)\left[1+\theta\left(N_{t}-1\right)\right]}
\end{gathered}
$$

which characterizes the corresponding evolution of the endogenous market structures in the short run. Under competition in quantities we have:

$$
N_{t+1}=(1-\delta)\left[N_{t}+\frac{A_{t}^{1+\varphi}}{\eta}\left(\frac{(\theta-1)\left(N_{t}-1\right) N_{t}^{\frac{2-\theta}{\theta-1}}}{v \theta C_{t}}\right)^{\varphi}-\frac{C_{t}}{\eta N_{t}^{1 /(\theta-1)}}\right]
$$

\footnotetext{
${ }^{16}$ It would be interesting to endogenize the exit rate as a countercyclical factor: this would strengthen our propagation mechanism, since it would enhance the countercyclicality of mark ups.
} 


$$
E_{t}\left\{\left(\frac{C_{t+1}}{C_{t}}\right)^{-1}\left[\frac{\eta(\theta-1)\left(N_{t}-1\right) N_{t}^{\frac{2-\theta}{\theta-1}}}{\theta}+\frac{\left(N_{t}+\theta-1\right) C_{t+1}}{\theta N_{t+1}^{2}}\right]\right\}=\frac{\eta(\theta-1)\left(N_{t}-1\right) N_{t}^{\frac{2-\theta}{\theta-1}}}{\beta(1-\delta) \theta}
$$

In general, one can show that the dynamic stochastic general equilibrium is saddlepath stable and convergent to a steady state endogenous market structure. Starting from a situation with a low number of firms, the equilibrium implies monotonic convergence to the steady state through an increase of both consumption and the number of firms.

\subsection{Endogenous Market Structures in the Long Run}

In this section we will briefly analyze the dynamic properties of the deterministic model (with $A_{t}=A$ for any $t$ ) along the transitional path and in steady state. For simplicity we will focus on the case of inelastic labor supply $(\varphi=0)$, in which the equation of motion of the number of firms does not depend on the form of competition and boils down to:

$$
N_{t+1}=(1-\delta)\left(N_{t}+\frac{A}{\eta}-\frac{C_{t}}{\eta N_{t}^{1 /(\theta-1)}}\right)
$$

Solving it for the consumption index in steady state, we obtain:

$$
C^{*}=A N^{* \frac{1}{\theta-1}}-\frac{\delta \eta N^{* \frac{\theta}{\theta-1}}}{1-\delta}
$$

At least for low levels of substitutability (low $\theta$ ), this is an inverted-U relation in $N^{*}$ : with few firms in steady state, the consumption index increases with the number of producers because of the love for variety effect, but with a large number of firms the index is negatively affected by a further increase in the number of producers because of the high savings necessary to replace the firms that exit in each period. ${ }^{17}$ The steady state number of firms that maximizes the steady state consumption index (and therefore utility) can be derived as $N^{G R}=(1-\delta) A / \delta \eta \theta$, where we refer to this as the golden rule number of producers. Any steady state with $N^{*}>N^{G R}$ would be dynamically inefficient, in the sense that higher levels of consumption could be permanently reached by reducing entry of firms.

\subsubsection{Steady state under Bertrand competition}

Under competition in prices the deterministic equilibrium system is given by (25) and (22). Evaluating the latter in steady state we have:

$$
C^{*}=\frac{(\theta-1) \eta[1-\beta(1-\delta)] N^{* \frac{1}{\theta-1}}\left(N^{*}-1\right)}{\beta(1-\delta)}
$$

which is a positive and convex relation in $N^{*}$ due to the role of the firms in producing consumption goods. The two expressions (26) and (27) could be represented in a phase diagram $\left(N_{t}, C_{t}\right)$ as for the traditional Ramsey model. Solving for the steady state endogenous market structure we obtain an explicit solution for the number of firms and, using (11), for the

\footnotetext{
${ }^{17}$ When substitutability between goods is high, the second effect always prevails and the above relation is monotonically decreasing; in particular, when goods are homogenous $(\theta \rightarrow \infty)$, we have $C^{*}=A-\delta \eta N^{*} /(1-$ $\delta)$, which is linearly decreasing in $N^{*}$.
} 
steady state mark up:

$$
\mu^{P}\left(\theta, N^{*}\right)=\frac{\theta \beta(1-\delta) A+\eta(\theta-1)(1-\beta)}{(\theta-1)[\beta(1-\delta) A-\eta \beta \delta]}
$$

One can easily verify the comparative statics. Higher productivity $A$ leads to higher demand and profits and therefore to more business creation, which increases the steady state number of firms and enhances competition while reducing the mark ups. When the costs of entry $\eta$ are high, profitability is low and the long run equilibrium is characterized by high concentration and high mark ups. When agents are more patient ( $\beta$ is larger), the interest rate is lower and the discounted sum of future profits is higher, which attracts more entry, strengthens competition and ultimately reduces the mark ups. When the risk of bankruptcy is high $(\delta$ is larger), there are only few firms in the long run and they apply a high mark up to their goods. Finally, higher homogeneity between goods (higher $\theta$ ) induces stronger competition and lower mark ups, with a negative impact on the number of firms.

As in the Ramsey model with perfect competition, the equilibrium is always dynamically efficient. ${ }^{18}$ However, the number of firms is excessive compared to the welfare maximizing solution - which BGM, 2008,b, have shown to be equivalent to the equilibrium emerging with constant mark ups $\mu=\theta /(\theta-1)$. Optimality can be restored with sales subsidies that are inversely related to the number of firms: therefore it is optimal to increase the sale subsidy when there are less firms than in the optimal steady state, and to decrease it when there are more firms, which corresponds to a countercyclical taxation. ${ }^{19}$

\subsubsection{Steady state under Cournot competition}

Under competition in quantities the deterministic equilibrium system is given by (25) and (24). In steady state the second relation becomes:

$$
C^{*}=\frac{\eta[1-\beta(1-\delta)](\theta-1) N^{* \frac{\theta}{\theta-1}}}{\beta(1-\delta)\left[1+\theta /\left(N^{*}-1\right)\right]}
$$

The steady state endogenous market structure can be derived in a similar way to the previous case, with a mark up $\mu^{Q}\left(\theta, N^{*}\right)$ exibiting the same comparative statics as before. ${ }^{20}$ However, the equilibrium with Cournot competition can be characterized by dynamic inefficiency $\left(N^{*}>N^{G R}\right)$ when the discount factor $\beta$ is high enough or the degree of substitutability $\theta$ is high enough. ${ }^{21}$ This outcome, which does not materialize in the baseline BGM model with monopolistic competition (whose equilibrium is actually fully efficient), is due to the tendency

\footnotetext{
${ }^{18}$ It can be verified that when the discount factor is small we have $N^{*} \leq N^{G R}$, and when $\beta \rightarrow 1$ the steady state number of firms converges to $N^{G R}+1-1 / \theta$. Therefore, taking the integer constraint in consideration, it turns out that the steady state number of firms cannot be larger than the golden rule number.

${ }^{19}$ In particular, introducing an ad valorem sale subsidy at rate $s_{t}^{s}$ financed with lump sum taxes on the firms as in BGM $(2008, \mathrm{~b})$, the optimal fiscal policy requires a countercyclical subsidy at the rate $s_{t}^{s}=1 / \theta\left(N_{t}-1\right)$, which is clearly decreasing in the number of firms and in the degree of substitutability between goods (See Etro, 2009). In case of elastic labor supply also the optimal labor tax would be countercyclical. Recently, Ghironi and Chug (2009) have studied optimal fiscal policy in a related model focusing on proportional dividend and labor taxation with state contingent debt.

${ }^{20}$ There is not an explicit solution for the long run number of firmsmark up (except in the case of homogenous goods, analyzed in Colciago and Etro, 2007).

${ }^{21}$ This can be verified in the limiting case of $\beta \rightarrow 1$ which leads to $N^{*}>N^{G R}$. A related case of dynamic inefficiency due to an excessive number of firms in a dynamic general equilibrium framework emerges in Etro (2004, 2008).
} 
toward excessive entry that characterizes models of competition in quantities with endogenous entry and to the dynamic link between savings and business creation in our model. When consumers are extremely patient they save too much, inducing excessive creation of firms that produce too little individually. The problem is more radical when the goods are highly substitutable because in that case the economy wastes resourses to create new firms that produce very similar goods. Welfare could increase both in the short and long run with a reduction of the number of firms and an increase in the production of each firm.

Moreover, even if dynamic efficiency holds, the equilibrium path is always characterized by excessive entry compared to the social planner solution. Again, full optimality can be restored with sales subsidies that are inversely related to the number of firms. ${ }^{22}$

Finally, notice that, given the same structural parameters, the endogenous market structure in steady state with competition in quantities implies a larger number of firms compared to the case of competition in prices. Even if, ceteris paribus, Cournot competition generates higher mark ups, endogenous entry attracts more firms and strengthens competition.

\section{Business Cycle Analysis}

This section has multiple purposes. First of all, we wish to evaluate the relative success of the models considered above at replicating the empirical facts described in the introduction, namely countercyclical markups together with procyclical profits and procyclical firms' entry. Second, we want to identify the extent to which the market structure influences the propagation of technology shocks throughout the economy.

Calibration of structural parameters is as follows. The time unit is meant to be a quarter. The discount factor, $\beta$, is set to the standard value for quarterly data 0.99 , while the rate of business destruction, $\delta$, equals 0.025 to match the U.S. empirical level of 10 per cent business destruction a year. The value of $v$ is such that steady state labor supply is equal to one. In this case the Frish elasticity of labor supply reduces to $\varphi$, to which we assign a value of four as in King and Rebelo (2000). We set steady state productivity to $A=1$. The baseline value for the entry cost is set to $\eta=1$. Our model allows for a large variety of combinations of substitutability between goods $(\theta)$ and mark up $(\mu)$, which in turn depends on the mode of competition. In in the remainder we will take $\theta=6$ as our baseline value since it is in line with the typical calibration for monopolistic competition and delivers markups levels belonging to the empirically relevant range. ${ }^{23}$ Nevertheless, to evaluate the dependence of the model's implications on the elasticity of substitution and for comparisons purposes with other models, we will also consider alternative values of $\theta$.

Notice that the combination of $A$ and $\eta$ affects the endogenous level of market power because a low entry cost compared to the size of the market leads to a larger number of competitors and thus to lower markups, and viceversa. However, the impulse response functions below are not qualitatively affected by values of $\eta$ within a reasonable range.

In what follows we will first study the impulse response functions to temporary supply shocks, and then we will evaluate the second order moments.

\footnotetext{
${ }^{22}$ Introducing an ad valorem sale subsidy at rate $s_{t}^{s}$ financed with lump sum taxes on the firms as in BGM $(2008, \mathrm{~b})$, the optimal fiscal policy requires a countercyclical subsidy at the rate $s_{t}^{s}=1 /\left(N_{t}-1\right)$, again decreasing in the number of firms.

${ }^{23}$ Oliveira Martins and Scarpetta (1999) provide estimates of price mark ups for US manufacturing industries over the period 1970-1992. In broad terms most of the sectoral markups defined over value added are in the range 30-60 per cent, while when defined over gross output they are in the range 5-25 per cent. In the latter case, high mark ups, over 40 per cent, are observed in few sectors.
} 


\subsection{Temporary productivity shocks}

In this section we show the qualitative reactions of the economy to a persistent technology shock. Technology is assumed to follow a first order autoregressive process given by $\hat{A}_{t}=$ $\rho_{A} \hat{A}_{t-1}+\varepsilon_{A t}$, where $\rho_{A} \in(0,1)$ and $\varepsilon_{A t}$ is a white noise disturbance, with zero expected value and standard deviation $\sigma_{A}$. Figures 3-4 depict percentage deviations from the steady state of key variables in response to a one percent technology shock with persistency $\rho_{A}=0.9$ in case of alternative market structures; time on the horizontal axis is in quarters.

We report the impulse response functions for different values of $\theta$ under respectively competition in quantities and in prices. Let us consider the baseline value for the elasticity of substitution between goods, $\theta=6$. Under Bertrand and Cournot competition the market structure is generated endogenously and the steady state mark ups are respectively 22 per cent and 36 per cent. As well known, when firms compete in prices the equilibrium mark ups are lower, which in turn allows for a lower number of firms to be active in the market: this implies that the model is characterized by a lower number of goods compared to the model with competition in quantities. Since this requires a smaller number of new firms to be created in steady state, lower mark ups are associated with a lower savings rate as well. In spite of these substantial differences in the steady state features of the economy, Figures 3 and 4 show that the quantitative reactions of the main aggregate variables to the shock are surprisingly similar in these two models with low substitutability.

Under both frameworks, the temporary shock increases individual output and profits on impact, which creates large profit opportunities. This attracts entry of new firms, which in turn strengthens competition and reduces the equilibrium mark ups. Therefore, our model manages to generate individual and aggregate profits that are procyclical despite mark ups being countercyclical, in line with the empirical evidence on business cycles. Notice that the dampening effect of competition on the mark ups is stronger under competition in quantities, where entry erodes profits margins faster than under competition in prices: ${ }^{24}$ this justifies higher entry and lower mark ups under competition in prices. The number of firms and the stock market value of the representative firm remain above their steady state levels along all the transition path. While the shock vanishes and entry strengthens competition, output and profits of the firms drop and the incentives to enter disappear. At some point net exit from the market occurs and the mark ups start increasing toward the initial level.

The impact of these reactions on the real variables resembles that of a basic RBC model, even if it derives from largely different mechanisms. Aggregate output jumps up and gradually reverts to the steady state level, being initially fueled by the reduction in the mark ups associated with entry and by the increase in labor supply associated with higher wages. Part of the increase in income (from higher wages and profits) is saved because the interest rate is increased by the sudden improvement of the profit opportunities. Savings are invested in firm creation, which in turn pushes output up and the interest rate down: the feedback effect on consumption generates its hump shaped path. However, contrary to standard models, here the impact of the shock on consumption is strengthened by a new competition effect. Entry of new firms strengthens competition and temporarily reduces the mark ups, which in turn boosts consumption.

To sum up, the productivity shock reduces not only the marginal cost (as already happens in the RBC model), but also the equilibrium mark up (which is zero in the RBC model and constant in the models with monopolistic competition), therefore the intertemporal substitution toward current consumption is stronger when the market structure is endogenous. In

\footnotetext{
${ }^{24}$ Recall that the mark up elasticity to the number of firms is larger under competition in quantities, as pointed out in the previous section.
} 

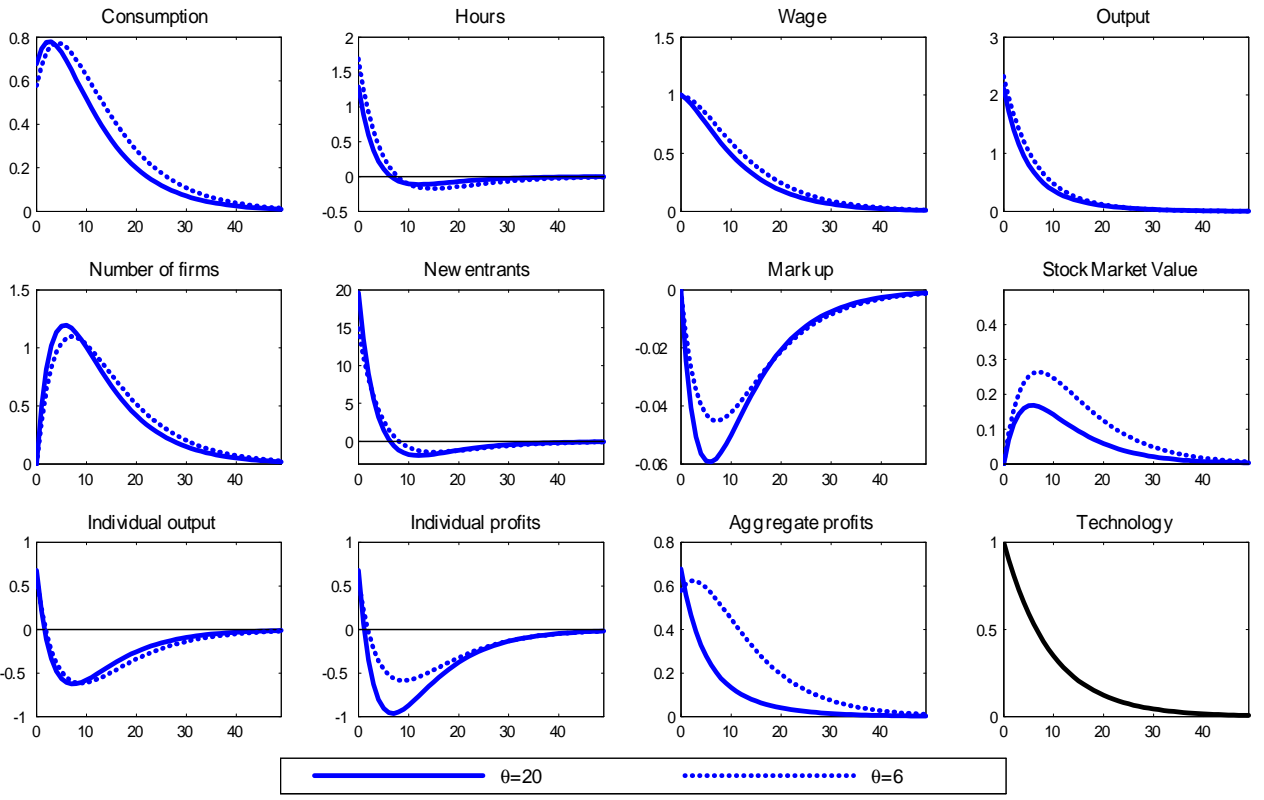

Figure 3: Bertrand competition. Impulse response function to a temporary technology shock.

other words, the impact of a temporary shock on consumption is magnified in the presence of endogenous market structures. ${ }^{25}$

As noticed earlier, our general model should be interpreted as a model of a representative sector with a potentially high degree of substitutability between goods. For this reason we consider an elasticity of substitution between goods $\theta=20$. In this case mark ups are markedly lower then in the previous case, 15 per cent under Bertrand competition and 28 per cent under Cournot competition, but the same qualitative results hold. Also, we consider the extreme case of homogenous goods $(\theta \rightarrow \infty)$, that corresponds to the typical assumption of the RBC literature: in such a case, our model with competition in quantities is compatible with positive (Cournot) mark ups and, as we can see in Figure 4, it is able to reproduce a similar propagation mechanism to the one we have just seen. On the contrary, under competition in prices and homogenous goods, the model collapses to one where mark ups vanish and entry does not take place because of the positive fixed costs of production (therefore we did not display this case in Figure 3). For this reason, and contrary to a long standing literature, we consider the model with competition in quantities as a more flexible tool for macroeconomic analysis of the business cycles in the presence of realistic (and endogenous) market structures.

The above comparison between two models featuring the same structural parameters but different modes of competition can be interesting in its own, but its interpretation is limited by the fact that in different markets different forms of competition take place - and most of the times we are not even able to screen between them. An alternative comparison which

\footnotetext{
${ }^{25}$ As well known, this effect is limited by the logarithmic preferences in consumption, which imply a unitary elasticity of intertemporal substitution. With an isoelastic utility function, the competition effect would be stronger when the elasticity of substitution is larger than unity.
} 

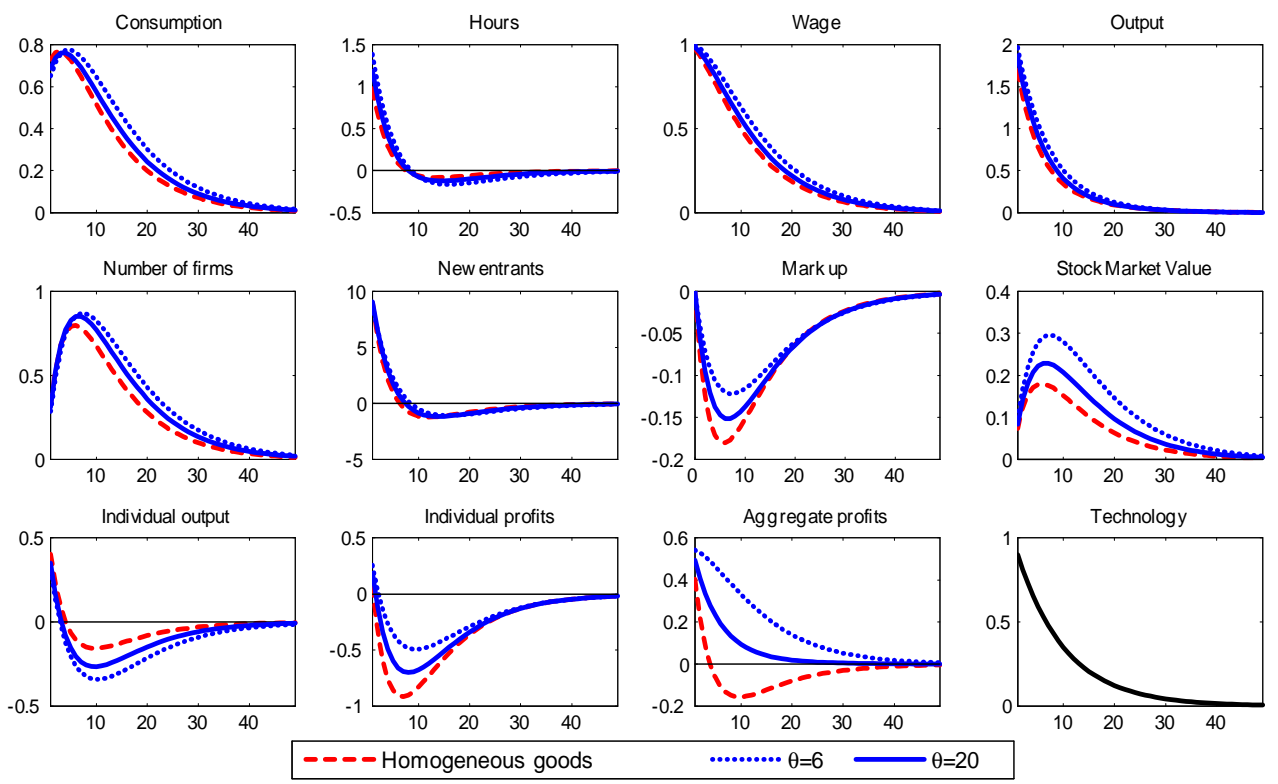

Figure 4: Cournot competition. Impulse response function to a temporary technology shock.

can be useful to understand the implications of endogenous market structures emerges when models with equal steady state mark ups are studied. In such a case all the aggregate ratios are the same as well, and different responses to a shock reveal fundamental differences of alternative modes of competition. To study a comparison of this second type, let us consider the model with competition in prices under the baseline calibration. (Figure 3). This model is characterized by a steady state mark up of 22 per cent. Under our parametrization, the same mark up emerges endogenously in a model of competition in quantities when the goods are homogenous, that is with $\theta \rightarrow \infty$ (Figure 4).

A comparison between the impulse response functions of these two cases with a mark up of 22 per cent (and therefore with equal steady state values) shows that the effect of competition on the markup is stronger in the case where firms compete in quantities and goods are homogenous. This affects the impact response of consumption, which has a stronger impact response under homogenous goods and competition in quantities rather than under low substitutability and competition in prices. ${ }^{26}$

\subsection{Second Moments}

To further assess the implications of endogenous market structures for the business cycle, we compute second moments of the key macroeconomic variables. In this exercise we follow the RBC literature and assume that the only source of random fluctuations are temporary exogenous technology shocks. We calibrate the productivity process as in King and Rebelo (2000), with persistence $\rho_{A}=0.979$ and standard deviation $\sigma_{A}=0.0072$. We use the same

\footnotetext{
${ }^{26}$ The same holds compared to low substitutability and competition in quantities, as we can see from Figures 3 and 4 jointly.
} 
process as in King and Rebelo (2000) for comparison purposes with the RBC literature and to verify the additional impact of our propagation channel for a given shock. We also computed and estimated a model based Solow residual (see Appendix B on data sources and Appendix $\mathrm{C}$ on a second moment analysis of a version of our model with capital accumulation where we parametrize the Solow residual according to our own estimates).

We report in Table 1 the statistics on US data (1947:1 / 2007:3) for output $Y$, consumption $C$, investment $I$, labor force $L$, aggregate profits $\Pi$ and the mark up $\mu .{ }^{27}$ We computed two alternative measures of the price markup. Since our model features a sunk cost in terms of units of labor, both of them allow for overhead labor costs. The measure reported in Table 1 is the labor-share based measure considered by Rotemberg and Woodford (1999). A second one is a model based measure and leads to similar qualitative results but is substantially more volatile and displays stronger countercyclicality. ${ }^{28}$

\begin{tabular}{ccccc}
\hline \hline Variable & $\sigma(X)$ & $\sigma(X) / \sigma(Y)$ & $E\left(X_{t}, X_{t-1}\right)$ & $\operatorname{Corr}(X, Y)$ \\
\hline$Y$ & 1.66 & 1 & 0.84 & 1 \\
$C$ & 1.19 & 0.75 & 0.78 & 0.76 \\
$I$ & 4.97 & 2,99 & 0.87 & 0.79 \\
$L$ & 1.82 & 1.10 & 0.90 & 0.88 \\
$\Pi$ & 8.08 & 4.87 & 0.76 & 0.67 \\
$\mu$ & 0.99 & 0.60 & 0.79 & -0.28 \\
\hline \hline
\end{tabular}

Table 1: Second moments. US data

Table 2 reports second moments of $Y, C, I \equiv N^{e} V, L, \Pi$, and mark up $\mu$ for our model with competition in quantities and with competition in prices under the baseline parameterization for the degree of substitutability between goods. ${ }^{29}$ Both frameworks provide a similar performance at reproducing some key features of the U.S. business cycle. Endogenous mark up fluctuations together with endogenous entry deliver a substantially higher output volatility with respect to the standard RBC model (1.51/1.52 against 1.39), ${ }^{30}$ almost matching the one emerging from US data. As emphasized above, we can capture procyclical profits and entry together with countercyclical mark ups as in the data. Our model provides a good match for the correlation of profits and mark ups with output, but it underestimates their variability, emphasizing the need for further work on the microfoundation of the endogenous market structures to better explain the high volatility of both profits and mark ups.

\footnotetext{
${ }^{27}$ Variables have been logged. We report moments of HP filtered variables with a smoothing parameter equal to 1600. Profits include both the remuneration of capital and the extra-profits due to market power: while we could not distinguish between the two, future research may try to do it.

${ }^{28}$ The model based measure of the price mark up takes into account that in our model the mark ups can be expressed as $\mu_{t}=C_{t} / w_{t}\left(L_{t}-L_{t}^{e}\right)$, i.e. as the inverse of the share of labor in consumption beyond the sunk quantity used to set up new firms (notice that $L_{t}^{e}$ represents hours required to produced new firms). Accordingly, we obtain $\sigma(\mu)=1.62, E\left(\mu_{t}, \mu_{t-1}\right)=0.81$ and $\operatorname{Corr}(\mu, Y)=-0.63$. The measure of the labor share used in our computation is given by the ratio of the compensation of employees in the nonfarm business sector to GDP. None of the cyclical properties we report are substantially altered using (GDPPROPRIETORS' INCOME) instead of GDP. For both the markup measures we consider, the ratio of the overhead quantity of labor to the steady state aggregate labor input is assumed to be 0.2 . This is within the range of values endogenously delivered at the steady state by our model under both competitive frameworks.

${ }^{29}$ Following BGM (2007) we report moments of data consistent variables, i.e. deflated using the average price index rather than the consumption based price index.

${ }^{30}$ The benchmark RBC model we consider is that by King and Rebelo (2000). Our utility function differs from theirs in the subutility from labour supply, but the second moments are equivalent under the same calibration.
} 
Moreover, mark up countercyclicality allows to strengthen the propagation of the shock on consumption through the competition effect. Both models display an absolute and relative (with respect to output) variability of consumption larger than that delivered by the RBC model (absolute: 0.78/0.78 against 0.6; relative: 0.51/0.52 against 0.43). Since low variability of consumption is a well known shortcoming of the RBC theory, the competition effect delivered by strategic interaction and endogenous entry appears to be a relevant channel to overcome it. Compared to the RBC framework, our model with endogenous market structures slightly improves the performance in terms of variability of hours $(0.85 / 0.77$ against $0.67)$.

Finally notice that the variability of output increases further (but that of consumption goes down) when lower degrees of substitutability between goods are taken in consideration, while it decreases (and the variability of consumption goes up) for higher degrees of substitutability, under both forms of competition.

\begin{tabular}{|c|c|c|c|c|}
\hline Variable & $\sigma(X)$ & 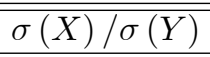 & $E\left(X_{t}, X_{t-1}\right)$ & $\operatorname{Corr}(X, Y)$ \\
\hline$Y$ & $1.52, \quad 1.51$ & 1 & $0.68, \quad 0.68$ & 1 \\
\hline$C$ & $0.78, \quad 0.78$ & $0.51, \quad 0.52$ & $0.77, \quad 0.76$ & $0.94, \quad 0.95$ \\
\hline$I$ & $5.89, \quad 7.56$ & $3.87, \quad 5.00$ & $0.65, \quad 0.64$ & $0.97, \quad 0.97$ \\
\hline$L$ & $0.85, \quad 0.77$ & $0.56, \quad 0.50$ & $0.65, \quad 0.64$ & $0.96, \quad 0.96$ \\
\hline$\Pi$ & $0.70, \quad 0.74$ & $0.46, \quad 0.49$ & $0.71, \quad 0.72$ & $0.99, \quad 0.98$ \\
\hline$\mu$ & $0.15, \quad 0.13$ & $0.10, \quad 0.08$ & $0.95, \quad 0.94$ & $-0.17, \quad-0.17$ \\
\hline
\end{tabular}

Table 2: Second moments under the baseline parameterization. Left: Cournot Competition; Right: Bertrand Competition

\section{Supply-side versus Demand-side Models}

BGM (2007) have offered an explanation for the empirical correlation of mark ups and profits with the business cycle resorting to a class of translog preferences, introduced by Feenstra (2003) and characterized by demand-side pricing complementarities. In such a framework goods become closer substitutes as the number of varieties produced in the economy increases. Net entry, which amounts to creation of new products, leads thus to a higher elasticity of substitution between goods which eventually translates into a lower mark up (which is given by $\mu\left(N_{t}\right)=1+1 /\left(\sigma N_{t}\right)$ where $\sigma>0$ is a free parameter determining the time-varying elasticity of substitution between varieties, that correspodns to $\left.\theta_{t}=1+\sigma N_{t}\right)$. For this reason we refer to this approach as to a demand-side explanation for mark up contercyclicality as opposed to the approach adopted in the our work, where countercyclicality results from strategic interactions on the supply side of the economy.

The purpose of this section is that of comparing the demand side and the supply side alternatives from both a qualitative and a quantitative point of view. To economize on space we will focus on Bertrand competition, however similar considerations as those made below apply to Cournot competition. ${ }^{31}$ We set the value of the elasticity of substitution, $\theta$, to 3.8, as in BGM (2007). This delivers a steady state mark up under Bertrand competition equal to $40 \%{ }^{32}$ Given our purpose we need to parametrize the value of $\sigma$ for the translog framework.

\footnotetext{
${ }^{31}$ Both a graphical and a quantitative comparison between the Cournot and the translog framework is available from the authors.

${ }^{32}$ This value of $\theta$ delivers a high mark up level compared to the estimates. We choose it for homogeneity
} 

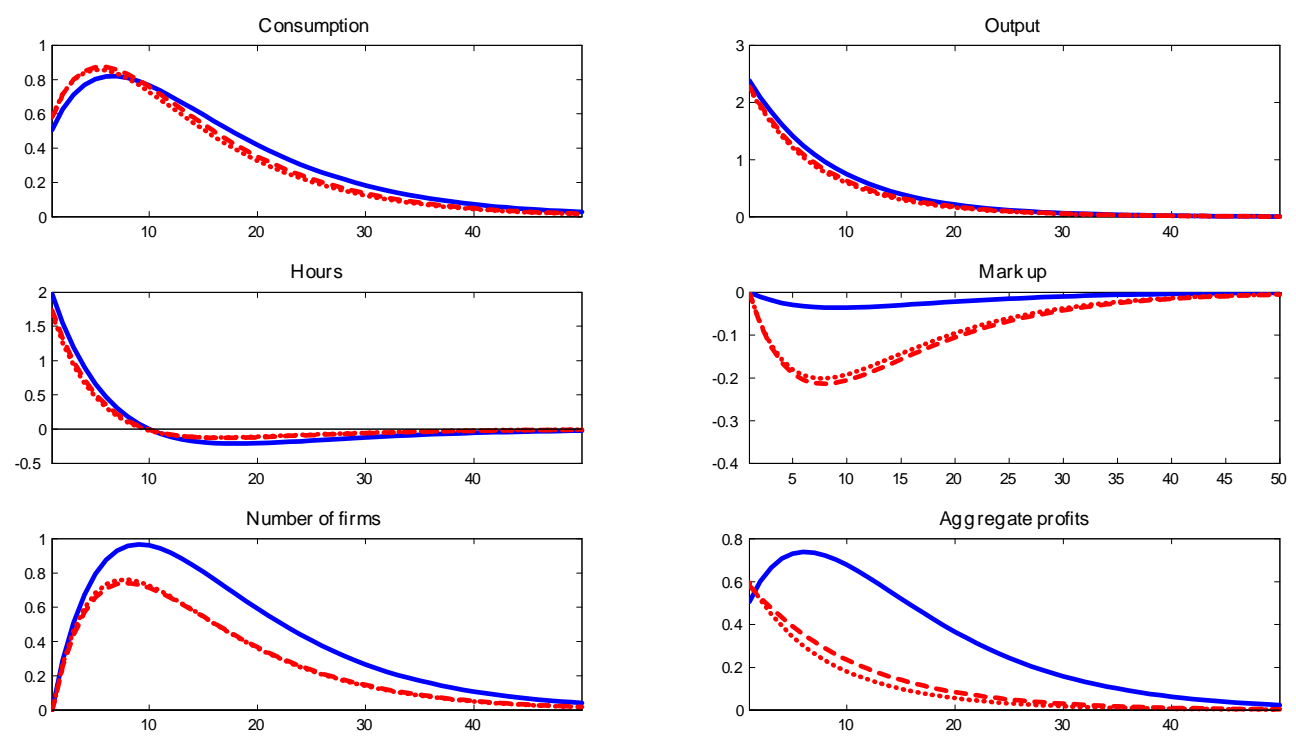

Bertrand - - - Translog ...... Translog BGM

Figure 5: Impulse Response Functions to a temporary technology shock

To do this we follow two alternative calibration strategies. In the first scenario we select $\sigma$ as to equate the steady state mark ups and the number of firms to those obtained under Bertrand. In the second scenario, instead, we set $\sigma$ as to equate across the two frameworks the (steady state) elasticity of substitution between goods. Under the selected value of $\theta$, the latter procedure delivers a value of $\sigma$ and a markup level, equal to $35 \%$, identical to those in the work by BGM. ${ }^{33}$

Figure 5 portraits the response to a temporary, one percent, technology shock of some relevant variables. Solid lines refer to Bertrand competition, dashed lines to the translog case under the first calibration scheme (named Translog), while dotted lines refer to the second calibration strategy (named Translog BGM).

Both the demand side and the supply side explanations deliver impulse response functions consistent with the empirical evidence presented in this and other works. Independently of the calibration strategy, the Bertrand model displays a higher and more persistent variation in the number of firms and profits and the translog framework shows a higher elasticity of the markup function with respect to the number of producers. ${ }^{34}$ Table 3 reports the second moments properties of the main macroeconomic variables under our model and those under the models with translog preferences. The features of the technology process are unchanged

with BGM. Notice, however, that results, including the relative performance of the models discussed in the remainder of the section, are not affected by considering the baseline value of the elasticty of substitution.

${ }^{33} \mathrm{BGM}$ choose the value of $\sigma$ as to equate the steady state mark up and the number of firms obtained under translog preferences to those obtained in the baseline version of their model, which features CES preferences with parameter $\theta=3.8$.

${ }^{34} \mathrm{As}$ robustness check we also computed the value of the elasticity of substitution which leads to the same markup and number of firms as in the baseline parametrization of the translog model in BGM. However, the relative performance of the models described in the text is unaffected. Results are available from the authors. 
with respect to those in the previous section. Again the performance of the two models is similar in many respects. Volatility of output and hours is closer to that found in the data under the Bertrand specification, while the model with translog preferences fares better at matching the volatility of consumption.

Although based on radically different mechanisms, the two hypothesis produce dynamics which are not distinguishable on the basis of aggregate data. Nevertheless, it is worth emphasizing that the supply side and the demand side explanations are designed to capture different effects. The BGM framework is better suited to describe an economy, or a sector, where entry is associated with product innovation: it identifies the effects on mark ups due to an increased number of varieties. In our framework, instead, entry increases competition and affects markups independently of the degree of sustitutability which characterizes goods provided by new entrants. The entry process in many traditional sectors and especially in the service sectors, which are a large part of developed economies, are mostly associated with the creation of new businesses in existing markets (as opposed to new markets). None of these traditional businesses will affect the extensive margin as defined in the statistics in terms of new consumer products, but they will be relevant nevertheless. ${ }^{35}$

Finally notice that product innovation often coexists with the creation of new businesses, and both a demand side and a supply side effect on mark ups will be present. For this reason the supply side and the demand side explanation should be understood as complementary, rather then alternative, explanations of the macroeconomic evidence we have tried to address.

\begin{tabular}{ccccc}
\hline \hline Var. & $\sigma(X)$ & $\sigma(X) / \sigma(Y)$ & $E\left(X_{t}, X_{t-1}\right)$ & $\operatorname{Corr}(X, Y)$ \\
\hline$Y$ & $1.61,1.48,1.46$ & 1 & $0.69,0.69,0.68$ & 1 \\
$C$ & $0.72,0.82,0.82$ & $0.45,0.55,0.56$ & $0.77,0.79,0.79$ & $0.94,0.92,0.93$ \\
$I$ & $6.26,5.17,5.36$ & $3.88,3.50,3.67$ & $0.67,0.65,0.64$ & $0.98,0.96,0.95$ \\
$L$ & $1.01,0.80,0.76$ & $0.62,0.55,0.52$ & $0.67,0.64,0.64$ & $0.97,0.95,0.94$ \\
$\Pi$ & $0.70,0.70,0.70$ & $0.43,0.48,0.48$ & $0.73,0.69,0.69$ & $0.97,0.99,0.99$ \\
$\mu$ & $0.20,0.19,0.18$ & $0.12,0.13,0.12$ & $0.95,0.94,0.94$ & $-0.11,-0.20,-0.22$ \\
\hline \hline
\end{tabular}

Table 3: Second moments. Bertrand Competition (left), Translog (center), Translog BGM (right)

\section{Capital accumulation}

In this section we augment the baseline model with endogenous investment in physical capital. Contrary to BGM (2007) we assume that capital is used solely in the production of final goods. ${ }^{36}$ Let us assume that final goods are produced with a standard Cobb-Douglas production function of the form:

$$
y_{t}(i)=A_{t} K_{t}(i)^{\alpha} L_{t}^{c}(i)^{1-\alpha}
$$

\footnotetext{
${ }^{35}$ To give an example of our idea, in a boom, profitable opportunities may lead new businesses to start, new restaurants to open, or new services to be provided, which will increase competition in the respective markets and reduce the mark ups. To the contrary, in a recession, lower demand may lead to rapid exit of firms so as to increase concentration and mark ups while production and (stock market) values of the firms go down.

${ }^{36}$ BGM (2007) introduce capital in the business creation sector as well. We could adopt the same approach and confirm their result for which the equilibrium exibits a cycling path, which is converging for high depreciation and diverging for low depreciation. The simpler approach adopted here avoids these phenomena.
} 

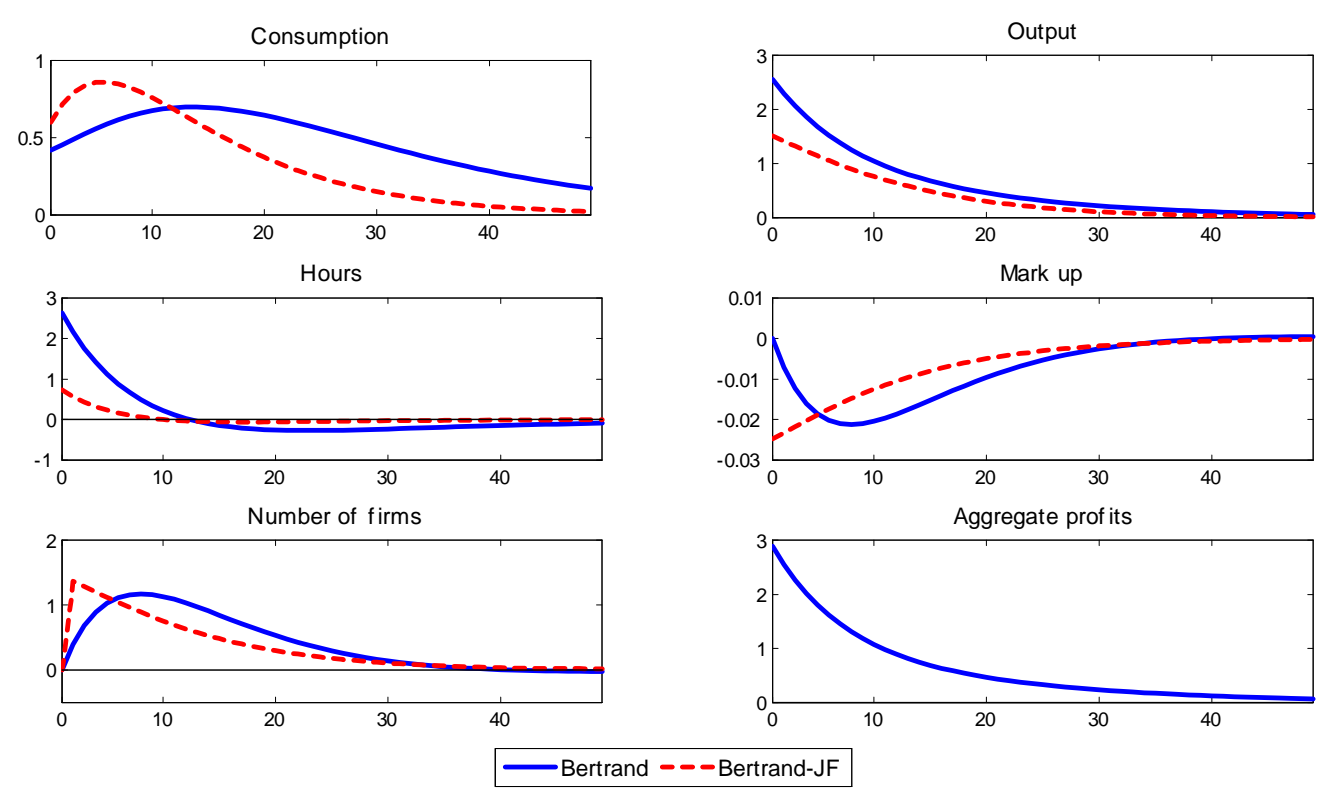

Figure 6: Impulse response function to a temporary technology shock.

where $0<\alpha<1$. New firms are created with the same technology as before.

The representative household holds the stock of capital and rents it to the producers of the final good. The aggregate stock of capital $K_{t}=\int_{0}^{1} N_{t} K_{t}(j) d j$ evolves according to:

$$
K_{t+1}=\left(1-\delta^{k}\right) K_{t}+I_{t}^{k}
$$

where $I_{t}^{k}$ is time- $t$ investment and $\delta^{k}$ is the rate of depreciation of physical capital. The household has a further intertemporal optimality condition with respect to the baseline model, which translates into the following Euler equation:

$$
C_{t}^{-1}=\beta E_{t} C_{t+1}^{-1}\left(1+r_{t+1}^{k}-\delta^{k}\right)
$$

where $r_{t}^{k}$ is the rental rate of physical capital.

Firms' pricing strategy is unchanged with respect to the baseline case, thus the definitions of the markup functions are not altered. The demand of inputs in the good producing sector is obtained by cost minimization, which requires:

$$
w_{t}=(1-\alpha)\left(\frac{K_{t}}{L_{t}^{c}}\right)^{\alpha} \frac{A_{t} N_{t}^{1 /(\theta-1)}}{\mu\left(\theta, N_{t}\right)}
$$

and:

$$
r_{t}^{k}=\alpha\left(\frac{K_{t}}{L_{t}^{c}}\right)^{\alpha-1} \frac{A_{t} N_{t}^{1 /(\theta-1)}}{\mu\left(\theta, N_{t}\right)}
$$

Using this and the labor equilibrium relation $L_{t}=L_{t}^{c}+L_{t}^{e}$, the aggregate resource contraint can be written as (see Appendix C): 


$$
Y_{t}=A_{t} K_{t}^{a}\left(L_{t}-L_{t}^{e}\right)^{1-\alpha} N_{t}^{1 /(\theta-1)}\left[1+\frac{(1-\alpha)}{\mu\left(\theta, N_{t}\right)}\left(\frac{L_{t}^{e}}{L_{t}-L_{t}^{e}}\right)\right]
$$

which emphasizes how the use of labor for business creation $L_{t}^{e}$ affects the effective total productivity and how the number of firms affects the production frontier.

The presence of capital accumulation implies that the new equation governing the dynamics of the number of firms reads as:

$$
N_{t}=(1-\delta) N_{t-1}+(1-\delta) \frac{A_{t}}{\eta}\left[L_{t}-\left(\frac{C_{t}+I_{t}^{k}}{A_{t} K_{t}^{\alpha}}\right)^{\frac{1}{1-\alpha}}\right]
$$

while the equations governing the dynamics of consumption remain unchanged. Therefore equation (22), in the case of Bertrand competition, or equation (24), in the case of Cournot competition, together with equations (31) and (35) fully determine the dynamics of $C_{t}, K_{t}$, and $N_{t}$. This model nests our basic model for $\alpha=0$ and the standard RBC model when $\eta \rightarrow 0$ and $\theta \rightarrow \infty .^{37}$

Jaimovich and Floetotto (2008) have developed an endogenous market structure model with physical capital accumulation which delivers countercyclical markups. Their baseline model, however, differs from our in various respects: a zero profit condition determines the number of firms in each time period, entry costs are fixed while firms are subject to fix costs of production. In Figure 6 we compare the performance delivered by our model (calibrated with $\alpha=1 / 3$ and $\left.\delta^{k}=0.025\right)$ to theirs. Both have been perturbed with the same persistent one percent technology shock. The steady state mark up and number of firms are held constant across the two frameworks. Since Jaimovich and Floetotto (2008) provide an explicit mark up function just for the case of Bertrand competition we will focus on price competition. ${ }^{38}$

\begin{tabular}{ccccc}
\hline \hline Variables & $\sigma(X)$ & $\sigma(X) / \sigma(Y)$ & $E\left(X_{t}, X_{t-1}\right)$ & $\operatorname{Corr}(X, Y)$ \\
\hline$Y$ & $1.76,1.31$ & 1 & $0.70,0.74$ & 1 \\
$C$ & $0.57,0.88$ & $0.32,0.67$ & $0.66,0.83$ & $0.97,0.94$ \\
$I$ & $4.79,2.48$ & $2.72,2.72$ & $0.71,0.68$ & $0.99,0.97$ \\
$L$ & $1.50,0.44$ & $0.85,0.33$ & $0.7,0.65$ & $0.98,0.86$ \\
$\Pi$ & 1.75, n.a. & 0.99, n.a. & $0.65 .$, n.a. & 0.99, n.a. \\
$\mu$ & $0.16,0.02$ & $0.09,0.01$ & $0.95,0.74$ & $-0.26,-1.00$ \\
\hline \hline
\end{tabular}

Table 4: Second moments. Our model with Bertrand competition and capital accumulation (left), JF model (right)

The interaction between sunk entry costs and oligopolistic behavior delivers a stronger propagation mechanism on hours and output with respect to a model where a zero profit condition holds in each period (but not on consumption). Treating firms as a state variable allows us to match the nonlinear time profile of the correlation between the markup and the

\footnotetext{
${ }^{37}$ Recall that just the Cournot case can deliver a positive markup when goods are homogeneous (i.e $\theta \rightarrow \infty$ )

${ }^{38}$ The comparison is carried out as follows. We consider the baseline value for the elasticity of substitution between goods $\theta=6$. We impose a steady state markup equal to $22 \%$, as in the earlier analysis of the Bertrand competition case, and let our model determine the steady state number of firms (the sunk entry cost is determined accordingly). Next, we turn to the Jaimovich and Floetotto (2008) model. We set the value of the elasticity of substitution between goods belonging to different sectors as in their paper (this is slightly larger that one), and impose a $22 \%$ markup. Finally the elasticity of substitution between goods belonging to the same sector is set as to obtain the same steady state number of firms as in our model.
} 
cycle. Output jumps on impact while, given the slow accumulation of producers, the mark up response is silent on impact and falls more in future periods. This correlation pattern is consistent with our VAR analysis.

In Table 4 we provide second moments for the two models under the baseline parametrization. Clearly, our model outperforms the model characterized by a zero profits condition in all dimensions (including a high variability of labor and profits) except for the relative variability of consumption. It has to be said that while the dynamics of the mark up and the number of firms is different by construction, the performance of the Jaimovich and Floetotto (2008) model substantially improves when a higher steady state markup together with a higher elasticity of substitution between sectoral goods is allowed. This, however, comes at the cost of having a very low number of competitors in the market. ${ }^{39}$

\section{Conclusions}

In this article we have studied a dynamic stochastic general equilibrium model where the structure of the markets is endogenous and accounts for strategic interactions of different kinds. The model belongs to the emerging literature on endogenous entry in the macroeconomy including Ghironi and Melitz (2005), BGM (2007, 2008,a), Jaimovich and Floetotto (2008) and others, and it provides further improvements in the explanation of the business cycle compared to the standard RBC framework. The interplay between sunk entry costs and strategic interactions between producers allows us to explain the procyclical variability of the profits together with the countercyclical variability of the mark ups. Nevertheless, we have emphasized a mark up and profit volatility puzzle: further examinations of alternative (static and dynamic) market structures should be aimed at matching the high levels of volatility that emerge from the empirical investigation of US mark ups and profits. Moreover, both the BGM demand side and the supply side explanations for countercyclical mark ups deliver impulse response functions to a technology shock which are consistent with the empirical evidence we have provided using US aggregate data. Future research should try to assess the relative merits of the two hypothesis by means of a microeconomic-level data analysis.

Many other extensions could be studied. The model could be expanded to an international context (see Ghironi and Melitz, 2005, for a related attempt, in which strategic interactions were not taken in consideration) to study international business cycle issues. The model with Bertrand competition could be also extended with monetary frictions as in BGM $(2008, a)$, Elkhoury and Mancini-Griffoli (2007) and Lewis (2009): in such a framework also a monetary shock would attract entry, strengthen competition and reduce mark ups so as to enhance the propagation mechanism. Moreover, the presence of strategic interactions between a limited number of firms would amplify the role of price rigidities. As well known, strategic complementarity leads firms to adjust less their prices when other firms do not adjust theirs (a phenomenon that is absent in standard New Keynesian models with a continuum of firms). One could introduce labor and credit market frictions to examine additional mechanisms of propagation of the business cycle. Finally, our model could be used to examine the impact of technological shocks affecting the market structure (as done in Etro, 2009b, for the

\footnotetext{
${ }^{39}$ We also compared the two models under Cournot competition. In particular we assumed that sectoral goods are homogeneous such that models features the same mark up function. This framework, is also directly comparable to the RBC framework which typically features homogeneous goods. Both models outperform the $\mathrm{RBC}$ model at replicating the variability of the main macroeconomic variables. The relative performance of the models is, instead, similar to that described in the case of Bertrand competition. See the companion paper Colciago and Etro (2007) for an extensive analysis of Cournot competition with homogeneous goods.
} 
introduction of a GPT as cloud computing that will turn part of the fixed costs of entry into variable costs)..$^{40}$

Our conclusion is that endogenous market structures do matter for macroeconomic issues. While the mainstream approach to the study of business cycles has been based either on perfect competition with constant returns to scale and zero mark ups or on monopolistic competition with positive but constant mark ups, we have shown that the interplay between strategic interactions and sunk costs, leading to a link between entry, profits and mark ups can substantially affect the way an economy reacts to shocks.

\section{Appendix}

\section{A. Analytical details}

The representative agent maximizes intertemporal utility (1) choosing how much to invest in bonds and risky stocks out of labor and capital income. Without loss of generality, bonds and stocks are denominated in terms of good 1 . The budget constraint expressed in nominal terms is:

$$
\begin{aligned}
& P_{1 t} B_{t+1}+\int_{0}^{1} P_{1 t} V_{k t}\left(N_{k t}+N_{k t}^{e}\right) s_{k t+1} d k+\int_{0}^{1} P_{k t} C_{k t} d k= \\
= & W_{t} L_{t}+\left(1+r_{t}\right) P_{1 t} B_{t}+\int_{0}^{1} P_{1 t}\left[\pi_{k t}\left(\theta, N_{t}\right)+V_{k t}\right] N_{k t} s_{k t} d k
\end{aligned}
$$

where $B_{t}$ is net bond holdings with interest rate $r_{t}, V_{k t}$ is the value of a firm from sector $k, N_{k t}$ and $N_{k t}^{e}$ are the active firms in sector $k$ and the new firms founded in this sector at the end of the period and $s_{k t}$ is the share of the stock market value of the firms of sector $k$ that are owned by the agent.

After solving the budget constraint for consumption of good 1 and substituting in the utility function, the optimality conditions with respect to $C_{k t}$ and $s_{k t+1}$ for each sector, and with respect to $B_{t+1}$ and $L_{t}$ are:

$$
\begin{gathered}
P_{k t} C_{k t}=P_{q t} C_{q t} \text { for any } k, q \in[0,1] \\
\frac{V_{k t}\left(N_{k t}+N_{k t}^{E}\right) P_{k t}}{P_{1 t} C_{k t}}=\beta E\left\{\frac{\left[\pi_{k t+1}\left(\theta, N_{k t+1}\right)+V_{k t+1}\right] N_{k t+1} P_{k t+1}}{P_{1 t+1} C_{k t+1}}\right\} \\
C_{1 t}^{-1}=\beta\left(1+r_{t+1}\right) E_{t}\left[C_{1 t+1}^{-1}\right] \\
\left(\frac{W_{t}}{P_{k t}}\right) C_{k t}^{-1}=v L_{t}^{\frac{1}{\varphi}}
\end{gathered}
$$

For each sector $k$, demand for the single goods is allocated according to (6) in the text. Each good $i=1,2, \ldots, N_{k t}$ in sector $k$ is produced by a single firm using labor according to (5). Uniperiodal nominal profits are given by $\Pi_{t}\left[x_{t}(i)\right]$ or $\Pi_{t}\left[p_{t}(i)\right]$ in the text according to whether competition in quantities or in prices takes place, and each firm chooses its strategy $x_{t}(i)$ or $p_{t}(i)$ to maximize the sum of the current profits and the value of the firm $V_{k t}(i)$ taking as given the strategies of the other firms. Notice that, in the absence of credible commitments to a sequence of future strategies, the optimal strategy is the one that maximizes current profits because this does not affect the future value of the firm. Endogenous market structures for each sector as described in the text generate a number of firms $N_{k t}$, mark ups $\mu\left(\theta, N_{k t}\right)$, and nominal profits $\Pi_{k t}=\left[1-1 / \mu\left(\theta, N_{k t}\right)\right] P_{k t} C_{k t}$ for each firm.

${ }^{40}$ See Etro (2009a) for a preliminary investigation of these extensions. 
Following Ghironi and Melitz (2005), we adopt a probability $\delta \in[0,1]$ with which any firm can exit from the market for exogenous reasons in each period. The dynamic equation determining the number of firms in each sector is then:

$$
N_{k t+1}=(1-\delta)\left(N_{k t}+N_{k t}^{e}\right) \quad \forall k
$$

which provides the dynamic path for the average number of firms:

$$
N_{t+1}=(1-\delta) \int_{0}^{1}\left(N_{k t}+N_{k t}^{e}\right) d k=(1-\delta)\left(N_{t}+N_{t}^{e}\right)
$$

where, of course, we have $N_{t} \equiv \int_{0}^{1} N_{k t} d k$ and $N_{t}^{e} \equiv \int_{0}^{1} N_{k t}^{e} d k$.

Market clearing in the asset markets requires $B_{t}=0$ for any $t$ in the bond market, and $s_{k t}=1$ for any sector $k$ in the stock market. In a symmetric equilibrium, the number of firms, the mark up and the profits are the same in every sector, which leads to the following equilibrium relations:

$$
\begin{gathered}
P_{k t}=P_{t} \quad C_{k t}=C_{t} \forall k \\
V_{t}\left(N_{t}+N_{t}^{E}\right) C_{t}^{-1}=\beta E\left\{\left[\pi_{t+1}\left(\theta, N_{t+1}\right)+V_{t+1}\right] N_{t+1} C_{t+1}^{-1}\right\} \\
C_{t}^{-1}=\beta\left(1+r_{t+1}\right) E\left(C_{t+1}^{-1}\right) \\
L_{t}=\left(\frac{w_{t}}{v C_{t}}\right)^{\varphi}
\end{gathered}
$$

The equation of motion for the average number of firms allows to rewrite the second relation as:

$$
V_{t}=\beta E_{t}\left\{(1-\delta)\left(\frac{C_{t+1}}{C_{t}}\right)^{-1}\left[\pi_{t+1}\left(\theta, N_{t+1}\right)+V_{t+1}\right]\right\}
$$

whose forward iteration provides the asset pricing equation:

$$
V_{t}=E\left\{\sum_{s=t+1}^{\infty}[\beta(1-\delta)]^{s-t}\left(\frac{C_{s}}{C_{t}}\right)^{-1} \pi_{s}\left(\theta, N_{s}\right)\right\}
$$

Notice that the equilibrium interest rate implicit in this equation is not governed as in the neoclassical approach (by the marginal productivity of capital), but by the dynamics of the stock market value, in particular by the stock market return in terms of capital gains and dividends which depend on the entry and competition process. Any shock that increases (decreases) the return on the investment in the stock market through a positive (negative) impact on short run profits or long run capitalization induces a positive (negative) effect on consumption growth through the impact on the equilibrium interest rate. The stock market affects the real economy not only because it reflects the productivity level in the economy, but also because it reflects the strategic interactions between firms and the entry/exit process due to various shocks.

Given the real marginal cost of production $w_{t} / A_{t}$, the equilibrium price in units of consumption is $p_{t} / P_{t}=\mu\left(\theta, N_{t}\right) w_{t} / A_{t}$. Since in the symmetric equilibrium $P_{t}=p_{t} N_{t}^{-1 /(\theta-1)}$, we have $p_{t} / P_{t}=$ $N_{t}^{1 /(\theta-1)}$ and therefore the equilibrium wage:

$$
w_{t}=\frac{A_{t} N_{t}^{1 /(\theta-1)}}{\mu\left(\theta, N_{t}\right)}
$$


Since total expenditure per sector is $E X P_{t}=P_{t} C_{t}=N_{t} y_{t} p_{t}$, we must have:

$$
C_{t}=N_{t} y_{t}\left(p_{t} / P_{t}\right)=y_{t} N_{t}^{\theta /(\theta-1)}=Y_{t} N_{t}^{1 /(\theta-1)}
$$

Individual profits are:

$$
\pi_{t}\left(\theta, N_{t}\right)=\frac{\left(\mu\left(\theta, N_{t}\right)-1\right)\left(C_{t}+G_{t}\right)}{\mu\left(\theta, N_{t}\right) N_{t}}
$$

To endogenize the number of firms, we assume that entry requires a fixed cost of entry which is proportional to the costs of production. In particular, entry requires an amount of labor force $\eta / A_{t}$ with $\eta>0$, for a total cost $F_{t}=\eta w_{t} / A_{t}$. The endogeneity of the market structure requires that this value equals the fixed cost of entry at each period, $V_{t}=F_{t}$ for any $t$, or:

$$
V_{t}=\frac{\eta w_{t}}{A_{t}}=\frac{\eta N_{t}^{1 /(\theta-1)}}{\mu\left(\theta, N_{t}\right)}
$$

Labor demand must be the sum of labor in the production of goods, which is equal to $L_{t}^{c}=$ $C_{t} / A N_{t}^{1 /(\theta-1)}$ (since $\left.C_{t}=A L_{t}^{c} N_{t}^{1 /(\theta-1)}\right)$, and in the creation of new firms, which must be equal to $L_{t}^{e}=N_{t}^{e} \eta / A_{t}$. By Walras' law, market clearing in the labor market is guaranteed.

Since the resource constraint of the economy can be rewritten in real terms as:

$$
Y_{t}=C_{t}+N_{t}^{e} V_{t}=N_{t} \pi_{t}\left(\theta, N_{t}\right)+w_{t} L_{t}
$$

The first equality can be used to express aggregate output in terms of the number of firms and labor used in business creation:

$$
Y_{t}=A_{t}\left(L_{t}-L_{t}^{e}\right) N_{t}^{1 /(\theta-1)}\left[1+\frac{L_{t}^{e}}{\mu\left(\theta, N_{t}\right)\left(L_{t}-L_{t}^{e}\right)}\right]
$$

while the second equality can be used to solve for the average number of new firms:

$$
N_{t}^{e}=\frac{1}{\eta}\left[A_{t}^{1+\varphi}\left(\frac{N_{t}^{1 /(\theta-1)}}{v \mu\left(\theta, N_{t}\right) C_{t}}\right)^{\varphi}-C_{t} N_{t}^{1 /(1-\theta)}\right]
$$

The above equations fully characterize the equilibrium, and they can be reduced to a system of two equations representing the dynamics of $N_{t}$ and $C_{t}$, namely:

$$
\begin{gathered}
N_{t+1}=(1-\delta)\left[N_{t}+\frac{A_{t}^{1+\varphi}}{\eta}\left(\frac{N_{t}^{1 /(\theta-1)}}{v \mu\left(\theta, N_{t}\right) C_{t}}\right)^{\varphi}-\frac{C_{t}}{\eta N_{t}^{1 /(\theta-1)}}\right] \\
E_{t}\left\{\left(\frac{C_{t+1}}{C_{t}}\right)^{-1}\left[\frac{\eta N_{t+1}^{1 /(\theta-1)}}{\mu\left(\theta, N_{t+1}\right)}+\frac{\left(\mu\left(\theta, N_{t+1}\right)-1\right) C_{t}}{\mu\left(\theta, N_{t+1}\right) N_{t+1}}\right]\right\}=\frac{\eta N_{t}^{1 /(\theta-1)}}{\beta(1-\delta) \mu\left(\theta, N_{t}\right)}
\end{gathered}
$$

which crucially depend on the mark up functions, and therefore on the form of competition.

Finally, we present the log-linearizations of the model. Assume inelastic labor supply for simplicity $(\varphi=0)$. Log-linearizing the general equilibrium system around its steady state we obtain the system for the local dynamics. Under Bertrand competition we have:

$$
\begin{aligned}
\hat{N}_{t+1}= & \left(1-\delta+\frac{(r+\delta)\left(N^{*}-1\right)}{N^{*}}\right) \hat{N}_{t}+ \\
& -\frac{(r+\delta)(\theta-1)\left(N^{*}-1\right)}{N^{*}} \hat{C}_{t}+\left[\delta+\frac{(r+\delta)(\theta-1)\left(N^{*}-1\right)}{N^{*}}\right] \hat{A}_{t}
\end{aligned}
$$


and:

$$
\begin{aligned}
\hat{C}_{t+1}= & \left(\frac{1+r}{1-\delta}\right) \hat{C}_{t}+\left(\frac{1+r}{1-\delta}\right)\left[\frac{1}{\theta-1}+\frac{N^{*}}{\left[1+\theta\left(N^{*}-1\right)\right]\left(N^{*}-1\right)}\right] \hat{N}_{t}+ \\
& +\left[\frac{1}{\theta-1}+\frac{N^{*}}{\left[1+\theta\left(N^{*}-1\right)\right]\left(N^{*}-1\right)}-\frac{(r+\delta) \theta N^{*}}{(1-\delta)\left[1+\theta\left(N^{*}-1\right)\right]}\right] \hat{N}_{t+1}
\end{aligned}
$$

This system can be explicitly solved for the two future variables in function of their current values. Under Cournot competition we have:

$$
\begin{aligned}
\hat{N}_{t+1}= & \left(1-\delta+\frac{(r+\delta)\left(N^{*}-1\right)}{N^{*}+\theta-1}\right) \hat{N}_{t}+ \\
& -\frac{(r+\delta)(\theta-1)\left(N^{*}-1\right)}{N^{*}+\theta-1} \hat{C}_{t}+\left[\delta+\frac{(r+\delta)(\theta-1)\left(N^{*}-1\right)}{\left(N^{*}+\theta-1\right)}\right] \hat{A}_{t}
\end{aligned}
$$

and:

$$
\begin{aligned}
\hat{C}_{t+1}= & \left(\frac{1+r}{1-\delta}\right) \hat{C}_{t}+\left(\frac{1+r}{1-\delta}\right)\left(\frac{1}{\theta-1}+\frac{1}{N^{*}-1}\right) \hat{N}_{t}+ \\
& +\left[\frac{1}{\theta-1}+\frac{1}{N^{*}-1}-\left(\frac{r+\delta}{1-\delta}\right) \frac{N^{*}+2(\theta-1)}{N^{*}+\theta-1}\right] \hat{N}_{t+1}
\end{aligned}
$$

which can be also solved for the two future variables in function of their current values. Stability of the system can be shown as in BGM (2007) with standard methods.

\section{B: Data sources}

Most of the data derive from FRED, the Federeal Reserve Economic Database of the Federal Reserve Bank of St. Louis. Below, we report in brackets the mnemonics of each series.

Compensation of Employees (COE): Billions of Dollars, Quarterly, Seasonally Adjusted Annual Rate (saar), 1947-01-01 2007-07-01.

Gross Domestic Product (GDP): Billions of Dollars, Quarterly, saar, 1947-01-01 2007-07-01.

Proprietors' Income with inventory valuation adjustment (IVA) and capital consumption adjustment (PROPINC): Billions of Dollars, Quarterly, saar, 1947-01-01 2007:07-01.

Personal Consumption Expenditure (PCEC): Billions of Dollars, saar, 1947-01-01 2007-07-01.

Corporate Profits with inventory Valuation Adjustment (IVA) and Capital Consumption Adjustment (CPROFIT): Billions of Dollars Quarterly, saar, 1947-01-01 2007-04-01.

Gross Domestic Product Implicit Price Deflator (PCEC): Index 2000=100, Quarterly, Seasonally Adjusted (sa), 1947-01-01 2007-07-01.

Hours of all Persons, nonfarm business sector (HOANBS): Index 1992=100, Quarterly, sa, 194701-01 2007-07-01.

Fixed Private Investment (FPI): Billions of Dollars, Quarterly, saar, 1947-01-01 2007-07-01.

The index of net business formation and the series measuring the number of new incorporations are supplied by the Brad\&Broadstreet corporation. The net business formation index runs from 1948:1 to $1995: 3(1967=100)$, for this reason we restrict our empirical analysis to this period. We thank Vivien Lewis for providing us the series on firms' data.

The annual data on the capital stock (KNIPQ), used to construct the TFP series, comes from the U.S. Bureau of Economic Analysis. The quarterly series has been obtained through linear interpolation. 


\section{C: The adjusted Solow residual}

Jaimovich and Floetotto (2008) argue that in the presence of markup variability the standard Solow residual is an upward biased estimator of technology shocks. The measure of technology used in our VAR analysis has been constructed along the lines suggested by them and takes into account the endogeneity of the market structure. To compute a model-consistent Solow residual we consider the version of our model with capital in the production of the final goods. The aggregate resource constraint reads as:

$$
Y_{t}=C_{t}+I_{t}^{k}+N_{t}^{e} V_{t}
$$

where the output of final good is:

$$
C_{t}+I_{t}^{k}=A_{t} K_{t}^{a}\left(L_{t}^{c}\right)^{1-\alpha} N_{t}^{1 /(\theta-1)}
$$

From this and (33) we obtain the wage $w_{t}=(1-\alpha)\left(C_{t}+I_{t}^{k}\right) / L_{t}^{c} \mu\left(\theta, N_{t}\right)$, which, together with the endogenous entry condition $V_{t}=\eta w_{t} / A_{t}$ and the labor requirement for firms creation $N_{t}^{e}=A_{t} L_{t}^{e} / \eta$ provides:

$$
N_{t}^{e} V_{t}=\frac{(1-\alpha)\left(C_{t}+I_{t}^{k}\right)}{\mu\left(\theta, N_{t}\right)}\left(\frac{L_{t}^{e}}{L_{t}^{c}}\right)
$$

Using (57) and the labor market equilibrium condition $L_{t}^{c}=L_{t}-L_{t}^{e}$ into the aggregate resource constraint yields:

$$
Y_{t}=\left(C_{t}+I_{t}^{k}\right)\left[1+\frac{(1-\alpha)}{\mu\left(\theta, N_{t}\right)}\left(\frac{L_{t}^{e}}{L_{t}-L_{t}^{e}}\right)\right]
$$

which generalizes (52). In data consistent terms (i.e. removing the variety effect), this can be rewritten as:

$$
\tilde{Y}_{t}=A_{t}\left[1+\frac{(1-\alpha)}{\mu\left(\theta, N_{t}\right)}\left(\frac{L_{t}^{e}}{L_{t}-L_{t}^{e}}\right)\right] K_{t}^{a}\left(L_{t}-L_{t}^{e}\right)^{1-\alpha}
$$

where $\tilde{Y}_{t}$ denotes the data consisten output. Taking logarithms:

$$
\log \tilde{Y}_{t}=\log A_{t}+\alpha \log K_{t}+(1-\alpha) \log \left(L_{t}-L_{t}^{e}\right)+\log \left[1+\frac{(1-\alpha)}{\mu\left(\theta, N_{t}\right)} \frac{L_{t}^{e}}{\left(L_{t}-L_{t}^{e}\right)}\right]
$$

A log-linear approximation to the relationship above yields

$$
\widehat{\widetilde{Y}}_{t}=\hat{A}_{t}+\alpha \widehat{K}_{t}+\frac{(1-\alpha)}{\left(1-l^{e}\right)} \hat{L}_{t}-\frac{\frac{(1-\alpha)}{\mu} \frac{l^{e}}{1-l^{e}}}{1+\frac{(1-\alpha)}{\mu} \frac{l^{e}}{\left(1-l^{e}\right)}}\left(\frac{1}{\left(1-l^{e}\right)} \hat{L}_{t}+\hat{\mu}_{t}\right)
$$

which delivers the adjusted Solow residual as

$$
\hat{A}_{t}=\widehat{\widetilde{Y}}_{t}-\alpha \widehat{K}_{t}-\frac{(1-\alpha)}{\left(1-l^{e}\right)}\left[\frac{1-\frac{\alpha}{\mu} \frac{l^{e}}{1-l^{e}}}{1+\frac{(1-\alpha)}{\mu} \frac{l^{e}}{\left(1-l^{e}\right)}}\right] \hat{L}_{t}+\frac{\frac{(1-\alpha)}{\mu} \frac{l^{e}}{1-l^{e}}}{1+\frac{(1-\alpha)}{\mu} \frac{l^{e}}{\left(1-l^{e}\right)}} \hat{\mu}_{t}
$$

This model-based Solow residual differs with from the Solow residual measured in a standard perfect-competition framework (i.e. $\hat{A}_{t}=\widetilde{\widetilde{Y}}_{t}-\alpha \widehat{K}_{t}-(1-\alpha) \hat{L}_{t}$ ) for two reasons. The first one is that part of the total labor input is used for the production of new firms, and the second is the presense of a time-varying mark up. 
We constructed the model-based solow residual defined by (58). ${ }^{41}$ This requires fixing the steady state mark up and the steady state value $l^{e}$. We use the value obtained in the Bertrand Model with capital under the baseline calibration, that is $\mu=1.22$ and $l^{e}=0.19$. In this case we obtain

$$
\hat{A}_{t}=\widehat{\widetilde{Y}}_{t}-0.333 \widehat{K}_{t}-0.807 \hat{L}_{t}+0.11 \hat{\mu}_{t}
$$

Finally we estimate the equation $\hat{A}_{t}=\rho_{A} \hat{A}_{t-1}+\varepsilon_{A t}$ with OLS. We obtain $\rho_{A}=0.95$ and $\sigma_{A}=0.00803 .{ }^{42}$ Next we simulate the Betrand model with capital with the latter parameterization for the technology process. Table 5 reports second moments. As expected, given the technology process is characterized by a lower autocorrelation coefficient and higher standard deviation with respect to the baseline case, the model delivers higher variability and lower persistence of the main macroeconomic variables with respect to those reported in the left column of Table 4 .

\begin{tabular}{ccccc}
\hline \hline Variable & $\sigma(X)$ & $\sigma(X) / \sigma(Y)$ & $E\left(X_{t}, X_{t-1}\right)$ & $\operatorname{Corr}(X, Y)$ \\
\hline$Y$ & 2.27 & 1 & 0.68 & 1 \\
$C$ & 0.50 & 0.22 & 0.64 & 0.92 \\
$I$ & 6.78 & 2.99 & 0.70 & 0.99 \\
$L$ & 2.27 & 0.97 & 0.68 & 0.98 \\
$\Pi$ & 2.25 & 0.99 & 0.68 & 0.99 \\
$\mu$ & 0.22 & 0.10 & 0.94 & -0.24 \\
\hline \hline
\end{tabular}

Table 5: Second moments. Bertrand competition and capital accumulation

\section{References}

Atkeson, A. and A. Burnstein (2008). Pricing to Market, Trade Costs, and International Relative Prices, The American Economic Review, 98, 5, pp. 1998-2031.

Bergin, P. and G. Corsetti (2008). The Extensive Margin and Monetary Policy, Journal of Monetary Economics, 55, pp. 1222-37.

Bernard, A., S. Redding and P. Schott (2008). Multi-Product Firms and Product Switching, mimeo, Yale University.

Bilbiie, F., F. Ghironi and M. Melitz (2007). Endogenous Entry, Product Variety, and Business Cycles, NBER WP 13646.

Bilbiie, F., F. Ghironi and M. Melitz (2008a). Monetary Policy and Business Cycles with Endogenous Entry and Product Variety, in NBER Macroeconomic Annual 200\%, Edited by D. Acemoglu, Kenneth Rogoff and Michael Woodford, pp. 299 - 353.

Bilbiie, F., F. Ghironi and M. Melitz (2008b). Monopoly Power and Endogenous Variety: Distortions and Remedies, NBER WP 14383.

Bils, M., 1987, The Cyclical Behavior of Marginal Cost and Price, The American Economic Review, 77, pp. 838-55.

Blanchard, O. and N. Kiyotaki (1987). Monopolistic Competition and the Effects of Aggregate Demand, The American Economic Review, 77, 4, pp. 647-66.

\footnotetext{
${ }^{41}$ Deviations of variables from the long run trend have been obtained detrending using a polynomial of time, as specified in the Introduction.

${ }^{42}$ For robustness we also sperimented with alternative values of $l^{e}$ (up to 0.25 ) and $\mu$ (up to 1.3) finding just minor differences. Notice that we repeated the same exercise for the traditional Solow residual obtaining respectively $\rho_{A}=0.95$ and $\sigma_{A}=0.0075$, values very close to those reported by King and Rebelo (2000) and used in the main text.
} 
Bresnahan, T. and P. Reiss (1987). Do Entry Conditions Vary across Markets?, Brookings Papers on Economic Activity, 3, pp. 833-81.

Broda, C. and D. Weinstein, 2009 Product Creation and Destruction: Evidence and Price Implications, The American Economic Review, in press.

Campbell, J. and H. Hopenhayn (2005). Market Size Matters, Journal of Industrial Economics, 53,1 , pp. 1-25.

Chatterjee, S. and R. Cooper (1993). Entry and Exit, Product Variety and the Business Cycle, NBER WP 4562.

Colciago, A. and F. Etro (2007). Real Business Cycles with Cournot Competition and Endogenous Entry, mimeo, University of Milan, Bicocca, Dept. of Economics.

Cooper, R. (1999). Coordination Games, Cambridge University Press.

Dedola, L. and S. Neri (2007). What does a Technology Shock do? A VAR Analysis with Model Based Sign Restrictions, Journal of Monetary Economics, 54, pp. 512-49.

Denicolò, V. and P. Zanchettin (2010). Competition, Market Selection, and Growth, ECONOMIC JOURNAL, forthcoming.

Devereux, M., A. Head and B. Lapham (1996). Aggregate Fluctuations with Increasing Returns to Specialization and Scale, Journal of Economic Dynamics and Control, 20, pp. 627-56.

Devereux, M. and K. M. Lee (2001). Dynamic Gains from International Trade with Imperfect Competition and Market Power, Review of Development Economics, 5, 2, pp. 239-55.

Elkhoury, M. and T. Mancini Griffoli (2007). Monetary Policy with Endogenous Firm Entry, mimeo, Swiss National Bank.

Etro, F. (2004). Innovation by Leaders, ECONOMIC JOURNAL, 114, 4, 495, pp. 281-303.

Etro, F. (2007). Endogenous Market Structures and Macroeconomic Theory, Review of Business and Economics, 52, 4, pp. 543-66.

Etro, F. (2008). Growth Leaders, Journal of Macroeconomics, 30, pp. 1148-72.

Etro, F. (2009a). Endogenous Market Structures and the Macroeconomy, Springer, New York and Berlin.

Etro, F. (2009b). The Economic Impact of Cloud Computing on Business Creation, Employment and Output in the E.U., Review of Business and Economics, 54, 2, pp. 179-208.

Etro, F. (2010). Endogenous market Structures and Strategic Trade Policy, International Economic Review, in press.

Feenstra, R. (2003). A Homothetic Utility Function for Monopolistic Competition Models, Without Constant Price Elasticity, Economic Letters, 78, pp. 79-86.

Galì, J., M. Gertler and D. López-Salido (2007a). Markups, Gaps, and the Welfare Costs of Business Fluctuations, Review of Economics and Statistics, 89, 1, pp. 44-59.

Galì, J., J. D. López-Salido and J. Vallés (2007b). Understanding the Eøects of Government Spending on Consumption, Journal of the European Economic Association, 5, 1, pp. 227-70.

Ghironi, F. and M. Melitz (2005). International Trade and Macroeconomic Dynamics with Heterogenous Firms, Quarterly Journal of Economics, pp. 865-915.

Ghironi, F. and S. Chug (2009). Optimal Fiscal Policy with Endogenous Product Variety, mimeo, Boston College.

King, R. and S. Rebelo (2000). Resuscitating Real Business Cycles, Ch. 14 in Handbook of Macroeconomics, J. B. Taylor \& M. Woodford Ed., Elsevier, Vol. 1, pp. 927-1007.

Kováč, E., V. Vinogradov and K. Žigić (2009). Technological Leadership and the Persistence of Monopoly under Endogenous Entry: Static versus Dynamic Analysis. mimeo, University of Bonn.

Kydland, F. and E. Prescott (1982). Time to Build and Aggregate Fluctuations, Econometrica, 50, 6, pp. 1345-70.

Jaimovich, N. and M. Floetotto (2008). Firm Dynamics, Markup Variations, and the Business Cycle, Journal of Monetary Economics, 55, 7, pp. 1238-52. 
Lewis, V. (2009). Business Cycle Evidence on Firm Entry, Macroeconomic Dynamics, in press.

Manuszak, M. (2002). Endogenous Market Structure and Competition in the 19th Century American Brewing Industry, International Journal of Industrial Organization, 20, pp. 673-932.

Manuszak, M. and C. Moul (2008). Prices and Endogenous Market Structure in Office Supply Superstores, Journal of Industrial Economics, 56, pp. 94-112.

Oliveira Martins, J. and S. Scarpetta (1999). The level and Cyclical Behavior of Mark-ups Across Countries and Market Structures, OECD Working Paper No. 213, OECD Publishing.

Rotemberg, J. and M. Woodford (1992). Oligopolistic Pricing and the Effects of Aggregate Demand on Economic Activity, Journal of Political Economy, 100, 6, pp. 1153-207.

Rotemberg, J. and M. Woodford (2000). The Cyclical Behavior of Prices and Costs, Ch. 16 in Handbook of Macroeconomics, J. B. Taylor \& M. Woodford Ed., Elsevier, Vol. 1, pp. 1051-135.

Vives, X. (1999). Oligopoly Pricing. Old Ideas and New Tools, The MIT Press, Cambridge.

Yang, X. and B. J. Heijdra (1993). Monopolistic Competition and Optimum Product Diversity: Comment, The American Economic Review, 83, 1, pp. 295-301. 